\title{
Effect of Intraplant Insect Movement on Economic Thresholds
}

\author{
C. W. HOY, ${ }^{1}$ C. E. MCCULLOCH, ${ }^{2}$ A. J. SAWYER, ${ }^{3}$ \\ A. M. SHELTON, AND C. A. SHOEMAKER* \\ Department of Entomology, Cornell University, \\ New York State Agricultural Experiment Station, \\ Geneva, New York 14456
}

\begin{abstract}
Environ. Entomol. 19(5): 1578-1596 (1990)
ABSTRACT A simulation model was constructed to examine the effects of intraplant spatial dynamics of the lepidopteran pest complex of cabbage on direct damage to the marketable parts of the plant. Diurnal fluctuations in microclimate for different parts of the crop canopy were simulated with sine functions. Larval development rates for each species were simulated with logistic functions of temperature, the development process with time-varying distributed delays, and feeding rates with exponential functions of temperature and larval age. Larval transition probabilities within the crop canopy were modeled with either constants or definite integrals of the Beta probability density function, the shape parameters of which were modeled as functions of temperature. The model provided a good fit to data on changes in intraplant distribution of these larvae and intraplant distribution of feeding damage. Evaluation of model predictions suggests that a threshold population density used for management decisions should not be static, but should be a complex function of species, larval age distribution, and forecast temperatures. A model like the one presented here could serve as that complex function.
\end{abstract}

KEY WORDS Insecta, simulation, model, pest management

CURRENTLY, many pest management programs rely on economic thresholds to determine when pest populations must be reduced to prevent economically important damage to a crop. The economic threshold is a simple model, which predicts that a certain amount of damage to the marketable parts of the crop will occur within a given period of time. Economic thresholds developed in the past (Stern 1973, Poston et al. 1983, Pedigo et al. 1986, Onstad 1987), however, did not take into account the spatial structure of multiple pests and their injury within the crop canopy. We hypothesize that intraplant movement of insect pests profoundly affects the amount of damage they cause on the marketable parts of their host plant. Herein we describe the construction and analysis of a simulation model we have used to explore the influence of intraplant spatial dynamics of insect pests on damage to the marketable parts of a crop. New techniques were developed to model intraplant movement as a function of microclimatic conditions within the crop canopy. Spatial dynamics of some species are influenced by the host plant (Hoy

\footnotetext{
'To whom reprint requests should be addressed. Current address: Department of Entomology, Ohio Agricultural Research and Development Center, The Ohio State University, Wooster, Ohio 4469l-6900.

${ }^{2}$ Biometrics Unit, Cornell University, Ithaca, N.Y. 14853

${ }^{3}$ USDA-ARS, Plant Protection Research Unit, U.S. Plant, Soil \& Nutrition Laboratory, Ithaca, N.Y. 14853.

' Department of Civil and Environmental Engineering, Cornell University, Ithaca, N.Y. 14853.
}

\& Shelton 1987), and this interaction was also captured in the model's mathematical form.

The system we studied includes fresh market cabbage and its lepidopteran pest complex: diamondback moth, Plutella xylostella L.; cabbage looper, Trichoplusia ni (Hübner); and imported cabbageworm, Artogeia rapae L. The larvae of each pest damage the crop by chewing holes in the leaves. The marketable parts of the cabbage crop, the head and four surrounding wrapper leaves, and the unmarketable parts, the remaining frame leaves, are vulnerable to this feeding damage. Therefore, the leaves that are fed upon, marketable or unmarketable, largely determine the economic importance of the damage.

Threshold population densities have been evaluated and used to manage cabbage lepidopteran pests. The thresholds proposed for fresh market cabbage, and for most crops, have typically been established by treating research plots at different population densities to estimate the maximum population density at which $5 \%$ (or some other arbitrary percentage) of cabbage heads will be rendered unmarketable. They are often called action thresholds, because the required economic analysis for a true economic threshold is usually impossible to perform. In practice, however, even the damage resulting from using a given action threshold can vary considerably. Leibee et al. (1984) tested several thresholds as well as weekly insecticide applications and found that all treatment regimes gave satisfactory results in two locations, while only the 
weekly application provided $>95 \%$ marketable heads (rated according to Greene et al. 1969) at two other locations. A threshold of one new feeding hole per plant, based on the results of Chalfant et al. (1979), yielded results as poor as $39.6 \%$ marketable heads in a subsequent test (Workman et al. 1980). Other examples in which results of using either calendar schedules or proposed thresholds vary in different locations or at different times have been reported as well (Sears et al. 1983, Shelton et al. 1983, Morisak et al. 1984, Kirby \& Slosser 1984, Cartwright et al. 1987). These varying results imply that growers require a more reliable means of predicting damage to their crop.

We have proceeded by first validating our model, comparing predictions with observed data, to determine whether the predictions are accurate enough to be useful for our analysis. Second, we have examined our more complex model's predictions of damage resulting from a static threshold population density when factors affecting intraplant spatial dynamics are varied. Results suggest that a useful model that predicts damage to the marketable parts of cabbage plants must incorporate intraplant spatial dynamics of the lepidopteran pest complex. Finally, to gain insight into the potential for use of our model as a management tool, we analyzed the sensitivity of model predictions to changes in the values of parameters and variables input by the user. Before discussing these analyses, we describe the model and how parameters were estimated.

\section{Model Description}

Simulation modeling involves forecasting changes in the value of state variables, which represent the state of a system, over time. The system described by this model includes populations of $P$. xylostella, A. rapae, and $T$. ni, a cabbage crop, and the influence of weather conditions. The cabbage crop is assumed to consist of mature or nearly mature (growth stage 8 or 9 , Andaloro et al. 1983b) plants of uniform size. State variables in the model are.

$N_{s k j}(t)$, the average number $N$ per plant of larvae of species $s$ and age subclass $k$ on stratum $j$ at time $t$ (in days),

where

$s=1,2,3$ representing $P$. xylostella, A. rapae, and $T$. $n i$, respectively,

$k=1,2, \ldots, 20$ representing subclasses in the development model and approximate age groups,

$j=1,2, \ldots, 5$ representing the head, four surrounding wrapper leaves, upper frame leaves, midframe leaves, and lower frame leaves, respectively.

Thus, the entire crop is represented by five vertical strata, and the entire population of each species is represented by an average number and age structure per plant on each of the five strata. Although distribution of larvae and their damage between plants is quite important, it goes beyond the scope of this study. An auxiliary variable,

$$
\begin{aligned}
E_{j}= & \text { average accumulated area of } \\
& \text { feeding }\left(\mathrm{cm}^{2}\right) \text { on stratum } j,
\end{aligned}
$$

is calculated to estimate damage to the crop.

Below we describe how the state variables change as larval development and movement are simulated, and how the auxiliary variable is calculated as the state variables change. We have observed that mortality due to naturally occurring agents over a 7-d period in commercial cabbage fields is either negligible or too rare to be a useful addition to the model. Diurnal temperature fluctuations in each of the different plant strata are incorporated as external variables. A list of variables with definitions and parameter estimates is given in Table 1. Inputs, each of the submodels, and output are described below for the model when run on a Macintosh computer (Apple Computer, Cupertino, Calif.).

Model Inputs. Initial values for the state variables and the microclimate submodel must be input by the user. These include a weather forecast, high and low temperatures and hours of sunshine for the next $7 \mathrm{~d}$, and the average number per plant of each species on each stratum, obtained by sampling a cabbage field. Initial age distribution is established for A. rapae and T. ni by providing separate averages for eggs, small (first and second instars), and large (third, fourth, and fifth instars) larvae. The initial age distribution is further defined by identifying the proportion of larvae, over the entire plant, estimated to be in each of the five instars. These initial values of state variables are input interactively in the screen depicted in Fig. 1 (the weather forecast is input similarly).

Microclimate. A cabbage plant offers insects a variety of microhabitats, from exposed and sunny leaves to leaves in almost perpetual shade; therefore, temperature is modeled separately for each of the plant strata. Temperature $\left({ }^{\circ} \mathrm{C}\right)$ in each stratum $j$ at a given time $t$ (days), temp, $(t)$, is modeled with sine functions, to simulate diurnal fluctuation in temperature, according to,

$$
\text { temp } p_{f}(t)=a v t e m p_{f}(t)+a m p_{f}(t) \operatorname{sine}(t 2 \pi)
$$

where

$$
\begin{aligned}
& \text { avtemp } p_{j}(t)=\text { the day's average ambient air tem- } \\
& a m p_{j}(t)=\text { half of the day's temperature range }
\end{aligned}
$$


Table 1. List of variables used in a model to predict feeding damage by Lepidoptera on cabbage. For parameter values estimated from our data, estimates (and standard errors in parentheses) are given

\begin{tabular}{|c|c|c|c|}
\hline Variable & Definition & $\begin{array}{l}\text { Type (or used } \\
\text { to calculate) }\end{array}$ & Estimated value \\
\hline$N_{s k j}(t)$ & $\begin{array}{l}\text { A verage number } N \text { per plant of larvae of species } s \text { in } \\
\text { age subclass } k \text { on stratum } j \text { at time } t \text { (in days) }\end{array}$ & State & f(time, rates) \\
\hline$E_{j}(t)$ & $\begin{array}{l}\text { Average accumulated area of feeding }\left(\mathrm{cm}^{2}\right) \text { on stratum } \\
j \text { at time } t\end{array}$ & Auxiliary & $f($ time, rates) \\
\hline$t e m p_{j}(t)$ & Temperature in stratum $j$ at time $t\left({ }^{\circ} \mathrm{C}\right)$ & Exogenous & $f($ time, forecast) \\
\hline $\operatorname{avtemp}_{f}(t)$ & Day's average temperature in stratum $j$ at time $t\left({ }^{\circ} \mathrm{C}\right)$ & Exogenous & From weather forecast \\
\hline$a m p_{j}(t)$ & $1 / 2$ day's range in temperature in stratum $j\left({ }^{\circ} \mathrm{C}\right)$ & Exogenous & From weather forecast \\
\hline$m_{1 j}, m_{2 j}$ & $\begin{array}{l}\text { Constants to calculate } a m p_{f}(t) \text { as a function of } a m p_{5}(t) \\
\text { and forecasted hours of sunshine }\end{array}$ & Exogenous & $\begin{array}{l}j=1: 0.6658(0.089), 0 \\
j=2: \text { (interpolated) } \\
j=3: 0.7634 \text { (0.487), } 0.0968(0.057) \\
j=4:(\text { interpolated) } \\
j=5: 0,0\end{array}$ \\
\hline$D E L_{s j}(t)$ & $\begin{array}{l}\text { Development time (days) for the larval period of } \\
\text { species } s \text { in stratum } j\end{array}$ & Rate & $\mathrm{f}\left(t e m p_{j}(t)\right)$ \\
\hline$C_{s}$ & $\begin{array}{l}\text { Maximum developmental rate for species } s \\
\quad \cdot\left[1+\exp \left(g_{1 s}+g_{2 s} T_{o p l}\right)\right]\end{array}$ & Rate & $\begin{array}{l}\text { P. xylostella, } 0.1429 \\
\text { A. rapae, } 0.0909 \\
\text { T. } n t, 0.1120\end{array}$ \\
\hline$T_{\text {opt }}$ & Temperature for maximum development rate $\left({ }^{\circ} \mathrm{C}\right)$ & Rate & $33^{\circ} \mathrm{C}$ for all species \\
\hline$g_{1 s,} g_{2 s}$ & $\begin{array}{l}\text { Empirically estimated constants for development rate } \\
\text { equations }\end{array}$ & Rate & $\begin{array}{l}\text { A. rapae: } 3.0707(0.201),-0.1624(0.012) \\
\text { P. xylostella: } 3.2317(0.118) \text {, } \\
\quad-0.1458(0.007) \\
\text { T. ni: } 4.2059(0.130)-0.1884(0.008)\end{array}$ \\
\hline$\frac{D E L_{s}^{2}}{S_{s}^{2}}$ & Relative dispersion in development time for species $s$ & Rate & $\begin{array}{l}\text { P. xylostella: } 40 \\
\text { A. rapae: } 30 \\
\text { T. ni: } 50\end{array}$ \\
\hline$F_{\mathrm{s}}$ & $\begin{array}{l}\text { Proportional shift in substages of the distributed delay } \\
\text { model of development }\end{array}$ & Rate & $\begin{array}{l}\text { P. xylostella: } 0.5 \\
\text { A. rapae: } 0.25 \\
\text { T. ni: } 0.6\end{array}$ \\
\hline$U(t)$ & Indicator variable in distributed delay & Rate & $f\left(F_{s}, D E L_{s}\right)$ \\
\hline$F P D_{s k j}(t)$ & $\begin{array}{l}\text { Area of leaf }\left(\mathrm{mm}^{2}\right) \text { consumed per larva of species } s \text { in } \\
\text { age subclass } k \text { per day on stratum } j \text { at time } t\end{array}$ & Rate & f(temperature, age) \\
\hline$h_{1 s}, h_{2 s}, h_{3 s}$ & $\begin{array}{l}\text { Empirically estimated constants to calculate leaf area } \\
\text { consumed per day as a function of temperature and } \\
\text { larval age }\end{array}$ & Rate & $\begin{array}{l}\text { P. xylostella: }-2.3055(1.08) \text {, } \\
\quad 0.5273(0.108),-0.0117(0.003) \\
\text { A. rapae: } 3.6466(1.25), 0.3183(0.124) \text {, } \\
\quad-0.0068(0.003) \\
\text { T. } n t: 2.5730(0.968), 0.4072(0.097) \\
\quad-0.0071(0.002)\end{array}$ \\
\hline \multirow[t]{3}{*}{$P_{s i f}(t)$} & \multirow{3}{*}{$\begin{array}{l}\text { Transition probabilities for species } s \text { at time } t \text { from } \\
\text { stratum } i \text { to stratum } j\end{array}$} & \multirow[t]{3}{*}{ Rate } & For $P$. xylostella: \\
\hline & & & {$\left[\begin{array}{lllll}.75 & .25 & 0 & 0 & 0 \\
.125 & .75 & .125 & 0 & 0 \\
0 & .125 & .75 & .125 & 0 \\
0 & 0 & .125 & .75 & .125 \\
0 & 0 & 0 & .2 & .8\end{array}\right]$} \\
\hline & & & $\begin{array}{l}\text { For } A . \text { rapae: } \\
{\left[\begin{array}{ccccc}.8 & .2 & 0 & 0 & 0 \\
.2 & .8 & 0 & 0 & 0 \\
.2 & .5 & .3 & 0 & 0 \\
.1 & .5 & .3 & .1 & 0 \\
.1 & .4 & .3 & .1 & .1\end{array}\right]}\end{array}$ \\
\hline $\begin{array}{l}c_{1}, c_{2}, d_{1} \\
\quad d_{2}\end{array}$ & $\begin{array}{l}\text { Constants }\left(c_{1}, d_{1}\right) \text { and coefficients of temperature }\left(c_{2}\right. \\
\left.d_{2}\right) \text { for estimating shape parameters of Beta proba- } \\
\text { bility density functions according to temperature. }\end{array}$ & Rate & $\begin{array}{l}\text { For } T, n i: \mathrm{f}\left(\operatorname{avg}_{f}(t)\right) \\
\text { See Hoy et al. }(1989)\end{array}$ \\
\hline$a_{i k}, b_{i k}$ & $\begin{array}{l}\text { Shape parameters for the Beta pdf's described above } \\
\text { (used to calculate transition probabilities for } T . n i \text { ) }\end{array}$ & Rate & $f\left(c_{1}, c_{2}, d_{1}, d_{2}, \operatorname{avg}_{1}(t)\right)$ \\
\hline
\end{tabular}

Thus, to simulate different microclimates in the different strata, we require a separate temperature average and range for each of the strata. These averages and ranges were simulated by a simple model based on energy balance relationships in a crop canopy.

Average temperature in each stratum is modeled as the forecast average ambient air temperature multiplied by a constant. The constant for the lower frame leaves was estimated as 1.0 (i.e., the temperature in the shaded lower frame is close to the temperature that would be measured in a standard weather recording shelter). The constants for the head and upper frame were modeled as the average ratio of temperature measurements (described below) in those strata to measurements taken in the lower frame $(1.03,1.04,1.05,1.025$ for the head, wrapper, upper frame, and midframe leaves, respectively). For the wrapper leaves and midframe leaves $(j=2$ and 4$)$ where temperature measurements were not available, average temperature is estimated by linear interpolation be- 
File Edit

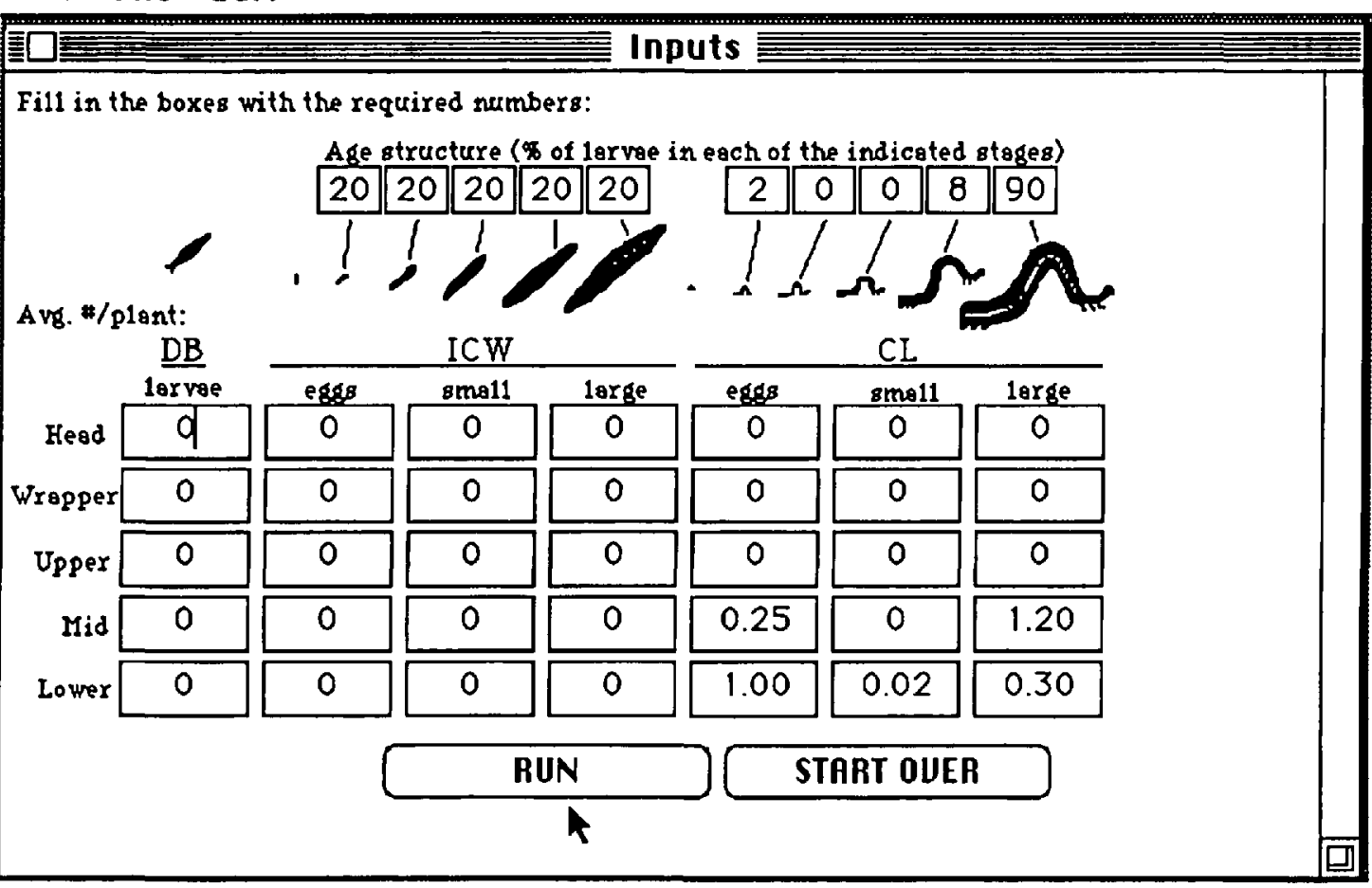

Fig. 1. Computer screen displaying the interactive input table for initializing a model to predict feeding damage by Lepidoptera on cabbage.

tween averages for the other strata $(j=1,3$ and 3,5 , respectively).

Like average temperature, the temperature range is assumed to be the same in the lower frame leaves as in the forecast for ambient conditions. Around the cabbage head, the observed temperature range was consistently narrower than it was under the lower frame leaves. The head has considerable mass and moderates the temperature around it. Therefore, the temperature range in stratum 1 , the head, is modeled as a proportion of the range in the lower frame. The temperature range in the upper frame is modeled as the range in the lower frame plus an effect of sunshine,

$$
\begin{array}{r}
a m p_{3}(t)=\underset{\quad}{a m p_{5}(t)+m_{13}+m_{23}} \\
\quad \text { (forecasted hours of } \\
\text { sunshine on day } t)
\end{array}
$$

where, $m_{1}$ and $m_{2}$ are empirically estimated constants. The upper frame leaves absorb radiant heat energy from sunlight, resulting in higher daytime temperatures than on the lower leaves; they radiate heat more easily at night than the lower leaves, because they are exposed to the sky, resulting in lower night temperatures in this part of the canopy.

Measurements were not available for the temperature range in the wrapper and midframe leaves. Temperature ranges in these strata were modeled similarly to the upper frame leaves, but the effect of sunshine was reduced to two-thirds that of the upper frame for the wrapper leaves, and one-third that of the upper frame for the midframe leaves, because these strata receive less sunlight.

To estimate the differences in average temperature and amplitude between strata, temperature was monitored on the undersides of the leaves in three of the strata (the head, upper frame leaves, and lower frame leaves) from 13 August to 23 October 1986 in research plots in Geneva, N.Y., as described in Hoy et al. (1989). Hourly temperature averages from 2 -min samples were recorded. Daily total solar radiation and ambient air temperatures were measured at the New York State Agricultural Experiment Station, weather station, Geneva, N.Y. Daily total solar radiation $\left(\mathrm{cal} / \mathrm{cm}^{2}\right)$ was divided by an estimate of average solar radiation per hour for Geneva, N.Y., during the time the measurements were taken, to approximate hours of sunshine. Estimated coefficients for the regression described above and for each of the constants are given in Table I (SAS Institute 1982). Quadratic and higher order polynomial coefficients for solar radiation were not significantly different from zero $(P=0.1228, n=43)$, indicating that the relationship could be described as linear. T-statistics on slope coefficients in these regression analyses also indicated that the linear effects of solar radiation on amplitude in the upper frame leaves were sig- 
nificant $(P<0.05, n=43)$. In addition, the effect of solar radiation on temperatures in the head was not significant $(P=0.2733, n=43)$.

Development Rates. Average larval development rates are calculated as a function of temperature for each species according to the algorithm proposed by Stinner et al. (1974),

$$
\frac{1}{D E L_{s j}(t)}=\frac{C_{s}}{\left(1+e^{B_{10}+B_{2 t} r_{j}(t)}\right)}
$$

where

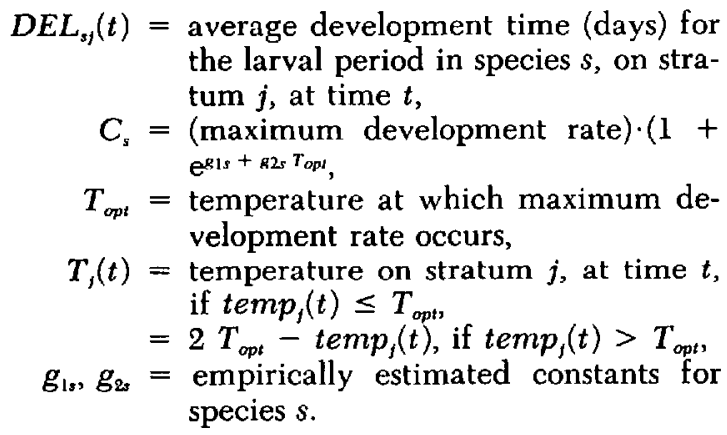

This model was used because it fits development rate data for T. $n i$ well (Butler et al. 1976), and it could easily be fit to data for the other species using standard nonlinear regression packages. Because the relationship between temperature and development time of $\boldsymbol{P}$. xylostella and A. rapae is qualitatively similar to that of $T . n i$, the function above was expected to provide a good fit to the data for these species as well. The $g_{1 s}$ and $g_{2}$, from equation 3 , were estimated by nonlinear regression (SAS Institute 1982) with the Marquardt computation method from data collected by A.M.S. and P. B. Baker (unpublished data) (Table 1). Minimum development times (days) for each species were estimated from data in the literature to be $8 \mathrm{~d}$ for P. xylostella, $12 \mathrm{~d}$ for A. rapae, and $9 \mathrm{~d}$ for $T, n i$, all at $33^{\circ} \mathrm{C}$. The inverse of these minimum development times was used to approximate each of the $C_{s}$ (equation 3 ) in the estimations.

Development times calculated using the algorithm with parameters calculated from A.M.S. and P. B. Baker's data were very similar to those reported in the literature for A. rapae and T. $n i$, whereas development times for $P$. xylostella were slightly longer than those previously reported (Fig. 2). The parameter estimates obtained from A.M.S. and P. B. Baker's unpublished data were used because the food source in their study, excised cabbage leaves, was most similar to the food source of the population being modeled. Because food source can affect larval development rate (Shorey et al. 1962, Jones \& Ives 1979, Wolfson 1982), use of these data, rather than data from the literature, should provide more accurate results.

Dispersion in development times was simulated by a time-varying distributed delay (Manetsch 1976) with controlled dispersion (Goudriaan 1973). This

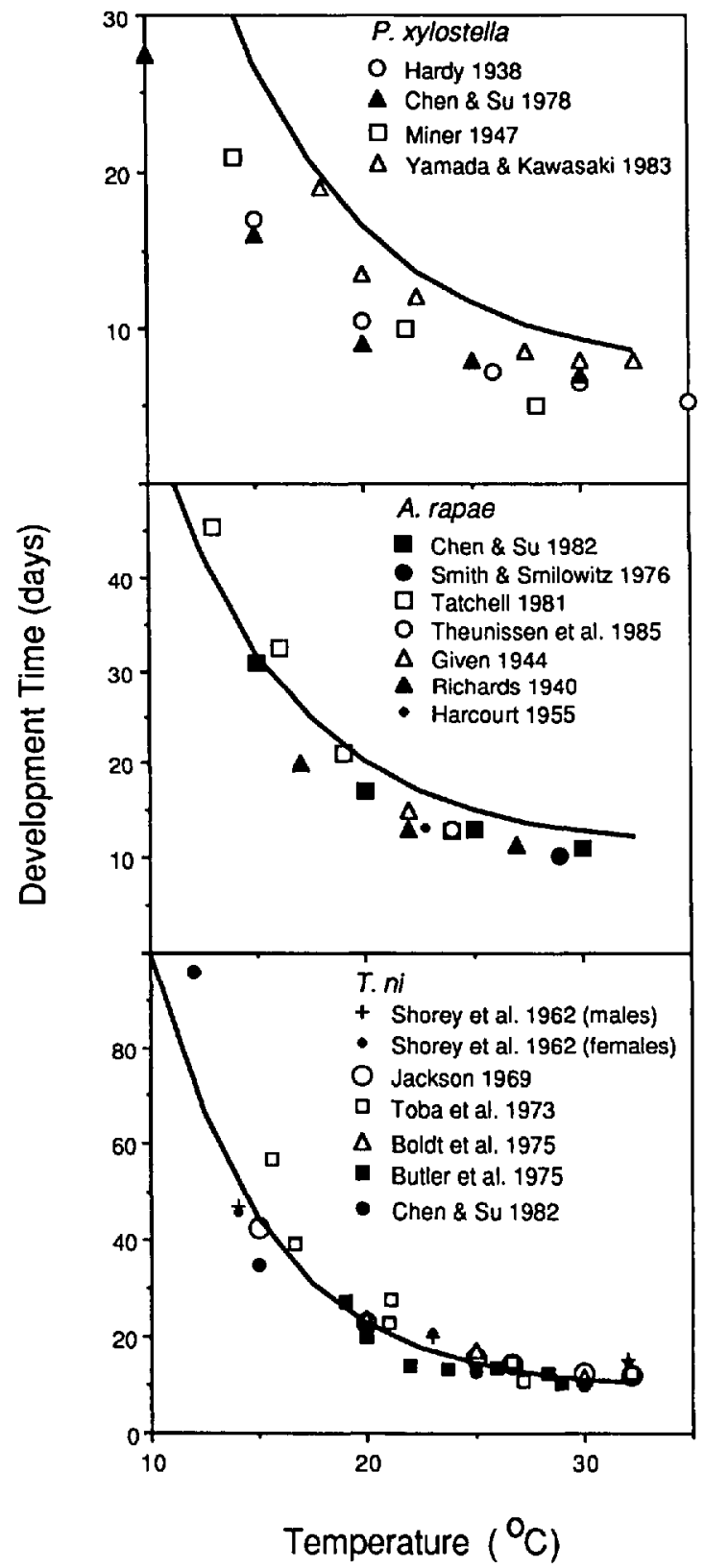

Fig. 2. Calculated development times for $P$. xylostella, A. rapae, and $T$. $n i$ larvae on cabbage (solid lines) compared with development times previously reported in the literature at specific temperatures.

algorithm shifts a proportion of the contents of each subclass to the next subclass at certain time steps. The number of time steps before each shift occurs and the proportion of the contents of each subclass shifted are determined by the average development time or delay, and the estimated dispersion in development times. The controlled dispersion model was used because fewer subclasses were required to represent the observed distribution of development times adequately (with 20 subclasses 
for each species, the output was similar to a delay without controlled dispersion using approximately twice the number of subclasses and twice the amount of computing time).

Programming the distributed delay with controlled dispersion yields the following difference equation - for the average number of pests per plant $N$,

$$
\begin{aligned}
N_{s k j}(t+\Delta t)= & N_{s k j}(t)+U(t) F_{s} \\
& \cdot\left[N_{s(k-1) !}(t)-N_{s k j}(t)\right]
\end{aligned}
$$

where

$$
\begin{aligned}
F_{s}= & 1-20 \frac{S_{s j}^{2}(t)}{D E L_{s}^{2}(t)}, \text { the proportion of each } \\
& \text { subclass shifted, } \\
S_{s j}= & \text { the standard deviation of development } \\
& \text { times for species } s, \\
U(t) & =1, \text { for } M(t)=1,2,3, \ldots, \\
& =0 \text { otherwise, } \\
M(t) & =\sum_{r=0}^{t} \frac{\Delta t}{F_{s} \frac{D E L_{s j}^{2}(\tau)}{20}} \\
\Delta t & =0.02 \mathrm{~d}, \\
\tau & =\Delta t, 2 \Delta t, 3 \Delta t, \ldots
\end{aligned}
$$

$\frac{S_{s}^{2}}{D E L_{3}^{2}}$ was found to be fairly constant for each species over three temperatures (A.M.S. and P. B. Baker, unpublished data), so $F$, was assumed to be a constant (Table 1 ). When programmed, $U(t)$ acts as an indicator for the shift of contents from each subclass to the next subclass, and $F$, gives the proportion of each subclass shifted.

The subclasses are used to approximate larval age groups, which are required to calculate agespecific feeding rates and to assign an age to the larvae that move between strata. Larvae on different strata develop at different rates because of different temperatures; therefore, larvae that move between strata must be placed in the appropriate age group at the new location (technically, the subclasses refer to relative maturity rather than chronological age).

The average number of a given instar per plant is divided evenly among delay subclasses designated to represent that instar as follows: $k=1-3$, 4-6, 7-10, 11-15, 16-20 for $A$. rapae instars one through five; and $k=1-3,4-6,7-9,10-14,15-20$ for $T$. $n i$ instars one through five. The number of subclasses used to represent each instar for a given species was based on estimates of the proportion of total larval development time spent in each instar (A.M.S. and P. B. Baker, unpublished data). For example, if approximately one-fourth of the larval period is spent in the last instar, the last instar would be represented by one-fourth of the subclasses, the last five. Summing over the appropriate subclasses gives the number of individuals in a given instar at a given time. In practice, instar designations are used only for initialization and reporting forecast numbers of small (first and second instars) and large (third, fourth, and fifth instars) larvae on a given stratum. We typically observe considerable overlap in $P$. xylostella life stages in the field. Therefore, the initial number of $P$. $x y$ lostella on each stratum is evenly divided among the 20 delay subclasses that represent this species, and only forecast total numbers of $P$. xylostella larvae are reported.

Feeding Rates. Accumulated feeding by each species on each stratum is calculated as a function of temperature and larval age. The larvae of each species tend to eat very little until the final instars, when feeding rates increase dramatically (Chen \& Su 1978, 1982). An exponential model is used to ensure that the predicted feeding rate is positive and to provide a qualitatively good fit. Plots of $\ln$ (feeding area/d) against proportion of development time completed at three temperatures appeared linear, with intercept close to zero and slope dependent on temperature. Tatchell (1981) studied consumption by $A$. rapae at lower temperatures and found that total consumption (leaf area in $\mathrm{cm}^{2}$ ) increased between 13 and $19^{\circ} \mathrm{C}$, then decreased between 19 and $24^{\circ} \mathrm{C}$; Boldt et al. (1975) found that $T$. $n i$ consumption increased from 20 to $25^{\circ} \mathrm{C}$ and then decreased between 25 and $30^{\circ} \mathrm{C}$. These studies and the plots described above indicate that the effects of temperature on feeding rates are not linear; rather, they are greater at intermediate temperatures and less at low and high temperatures. We describe this effect of temperature on feeding rate by defining the slope in a regression of $\ln$ (feeding area/d) predicted by larval age as a quadratic function of temperature. Feeding rate per larva per day as a function of temperature and age of the larva can then be expressed as an exponential function,

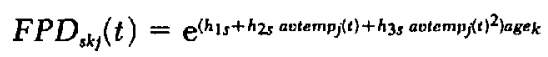

where

$$
\begin{aligned}
F P D_{s k f}(t)= & \text { feeding area }\left(\mathrm{mm}^{2}\right) \text { per day per } \\
& \text { larva of species } s \text { in subclass } k \text { on } \\
& \text { stratum } j \text { at time } t, \\
\text { avtemp }_{j}(t)= & \text { day's average temperature in } \\
& \text { stratum } j \text { at time } t, \\
\text { age }_{k}= & \text { average proportion of larval de- } \\
& \text { velopment completed by sub- } \\
& \text { class } k \\
= & \left(\frac{k}{20}-\frac{1}{40}\right),
\end{aligned}
$$

$h_{1 s}, h_{2 s}, h_{3 s}=$ empirical constants for species $s$.

If each subclass is assumed to represent $\frac{1}{20}$ of a larva's development time, average feeding rate for each subclass in the distributed delay is calculated at the midpoint of the class, age $_{k}=\left(\frac{k}{20}-\frac{1}{40}\right)$ in Equation (6). Thus, accumulated feeding in $\mathrm{cm}^{2}$ is summed over all age classes of all species and all 
previous time steps by,

$$
E_{i}(t)=\sum_{\tau=0}^{1} \sum_{s=1}^{3} \sum_{k=1}^{20} \frac{\left[N_{s k j}(\tau) F P D_{s k j}(\tau)\right]}{100} \Delta t
$$

where,

$$
\begin{aligned}
E_{j}(t)= & \text { area of feeding }\left(\mathrm{cm}^{2}\right) \text { on stratum } j \text { accu- } \\
& \text { mulated at time } t, \\
\tau= & \Delta t, 2 \Delta t, 3 \Delta t, \ldots, \\
\Delta t= & 0.02 \mathrm{~d} .
\end{aligned}
$$

The three empirical constants $\left(h_{1 s}, h_{2 s}\right.$, and $h_{3}$ in Equation 6) for estimating feeding rates as a function of temperature and larval age were estimated by multiple linear regression (SAS Institute 1982) of the natural log of feeding/day $\left(\mathrm{mm}^{2}\right)$ on age, age temperature, and age temperature ${ }^{2}$ (Table 1 ). The measure of larval age was the proportion of larval stage completed, or days the larva had lived so far, divided by total days spent by that larva from eclosion to pupation. Measurements of area of cabbage leaf consumed each day of the larval period for each of 20 larvae/replicate, and three replicates/temperature at $16.7,21.1$, and $26.7^{\circ} \mathrm{C}$ for each species were taken by A.M.S. and P. B. Baker (unpublished data). Inspection of predictions (Fig. 3) compared with data reported in the literature (Harcourt et al. 1955; McEwen \& Hervey 1960; Rahman 1970; Harper 1973; Boldt et al. 1975; Chen \& Su 1978, 1982; Samson \& Geier 1983; Theunissen et al. 1985) indicates that the feeding rate model fit well. Data on feeding by $A$. rapae reported by Tatchell (1981) indicate much higher rates than those we estimated, but Tatchell's data disagree with the other literature cited above as well. As in the case of development rates, we used the A.M.S. and P. B. Baker data, because the food source was cabbage leaf, so these data should be most appropriate.

Movement Rates. Larval movement is simulated with discrete time transition probability matrices, because observed larval movements were discrete in time. Movement of late instar T. $n i$ is correlated with microclimate (Hoy et al. 1989) and must be modeled accordingly. The transition probabilities for late instar $T$. ni are modeled as definite integrals of the Beta probability density function (pdf) with shape parameters $a_{i}(t)$ and $b_{i}(t)$, which depend on temperature and the stratum larvae are moving from,

$$
\begin{aligned}
& p_{3 i j}(t) \\
& \quad=\int_{\frac{j-1}{5}}^{\frac{j}{5}} \frac{1}{\mathrm{~B}\left[a_{i}(t), b_{i}(t)\right]} u^{[\alpha(t)-1]}(1-u)^{\left[b_{(t)-1]} \mathrm{d} u\right.}
\end{aligned}
$$

where

$$
\begin{aligned}
p_{3 j}(t)= & \text { the probability of a } T . n i \text { (species } \\
& \text { 3) late instar moving from stratum } \\
& i \text { to stratum } j \text { during one day, } \\
a_{i}(t)= & e^{c_{1}+c_{2} \text { avtempi }(t)}, \\
b_{i}(t)= & e^{\left.d_{1}+d_{2} \text { avtempi } i t\right)},
\end{aligned}
$$
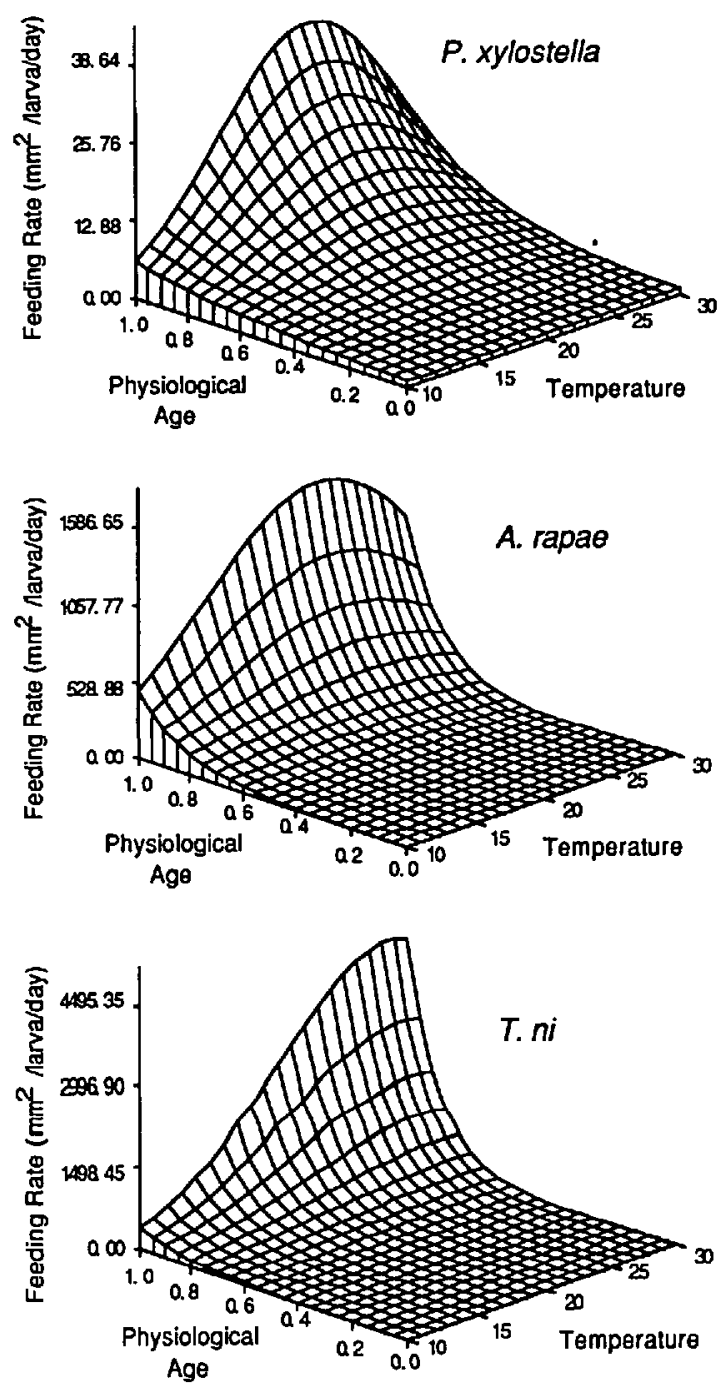

Fig. 3. Predicted feeding rates of $P$. xylostella, $A$. rapae, and $T$. ni on cabbage.

\section{$c_{1}, c_{2}, d_{1}, d_{2}=$ constants estimated by maximum likelihood as described by Hoy et al. (1989).}

Because the shape parameters for the Beta distribution, $a_{i}$ and $b_{i}$, change with temperature, the shape of the distribution and value of the integrals described in Equation (8) change accordingly. Higher temperatures tend to result in greater probability of movement, and higher probability of movement towards the lower leaves than towards the head; lower temperatures tend to result in lower probability of movement, and higher probability of movement towards the head than towards the lower leaves.

The elements of the transition probability matrices for $P$. xylostella and A. rapae are estimated from observations reported in the literature (Harcourt 1963, 1966; Chua \& Lim 1979; Samson \& 


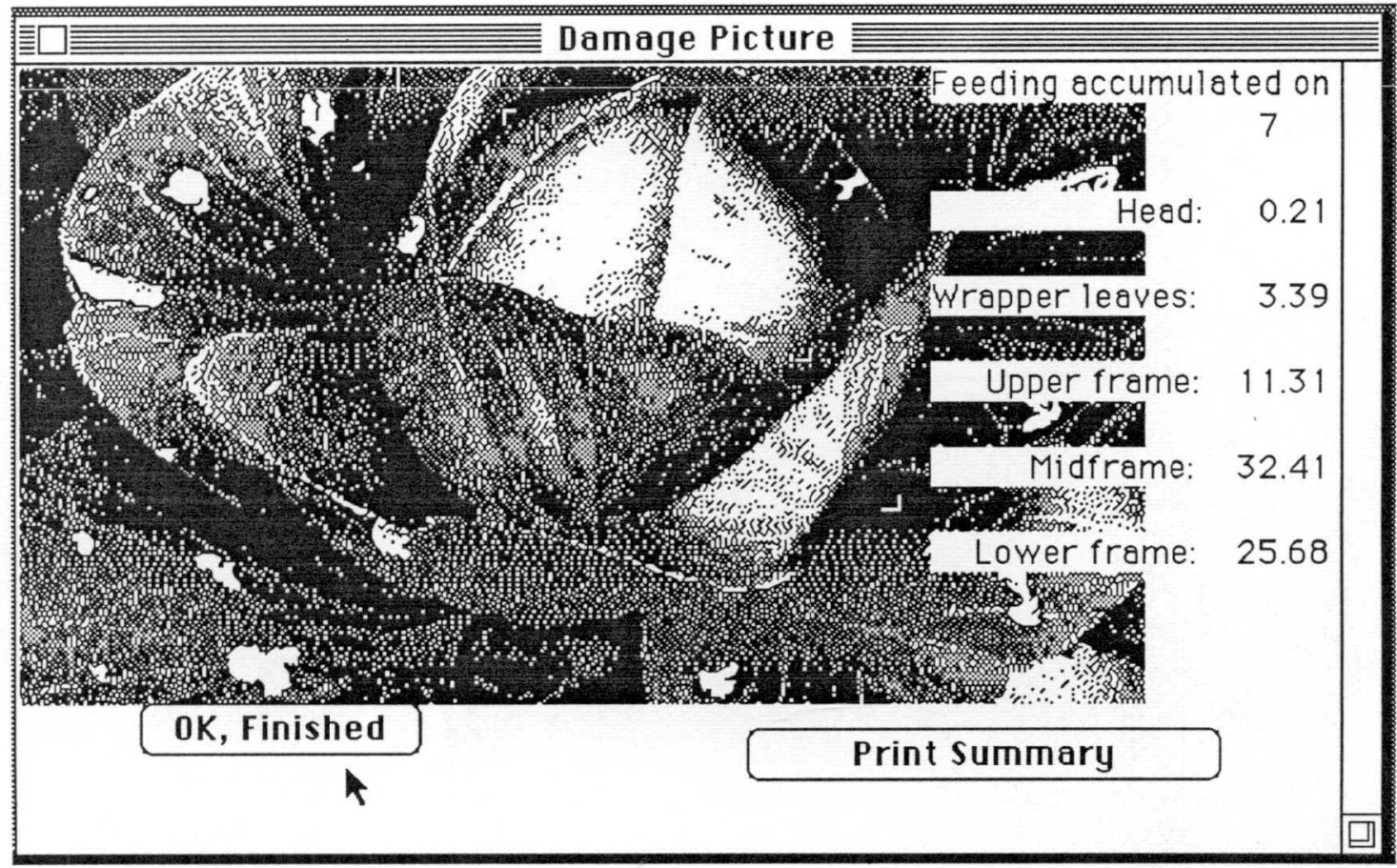

Fig. 4. Computer screen displaying output from a simulation model of feeding damage by Lepidoptera on cabbage.

Geier 1983; Salinas 1984) and our own observations. Our observations for these species were the frequency of movements by larvae marked with fluorescent powder and visually censused at $\approx 1-h$ intervals in research cabbage plots near Geneva, N.Y. The number of these observations was not sufficient to estimate individual transition probabilities, so the data were used roughly to estimate frequency of movement and probability of moving up or down on the plant. For $P$. xylostella, the frequency of movement was low, and approximately equal numbers of upwards and downwards movements were observed. For A. rapae, virtually all late instars were observed to move upwards to the head or wrapper leaves, as noted by Harcourt (1963, 1966) and Hoy \& Shelton (1987). Transition probabilities that reflect these observations were chosen for these two species and are given in $\mathrm{Ta}-$ ble 1 .

The change in state variables due to movement is thus calculated by,

$$
N_{s k j}(t+\Delta t)=\sum_{i=1}^{5} N_{s k j}(t) p_{s i j}(t) I(t+\Delta t)
$$

where

$$
\begin{aligned}
k & =13,14, \ldots, 20 \text { for } s=1 \\
k & =10,11, \ldots, 20 \text { for } s=2 \text { or } 3 \\
I(t+\Delta t) & =1 \text { if }(t+\Delta t)=1,2,3, \ldots, \\
& =0 \text { otherwise, } \\
\Delta t & =0.02 \mathrm{~d} .
\end{aligned}
$$

Movement is simulated only once each day, and because the time step for the model is $1 / 50$ of a day, the indicator $I(t)$ is used to determine when the movements occur. The values of $k$ given above are chosen so that movement is simulated only for older larvae, which are represented by higher values of $k$ ( $k \geq 13$ for $P$. xylostella and $k \geq 10$ for A. rapae or $T, n i)$.

Model Output. The output generated, using the equations described above, is a summary of the values of state variables and the value of the auxiliary variable each day for the next $7 \mathrm{~d}$. This is presented on the computer screen depicted in Fig. 4. The number of large and small larvae of each species on each stratum also can be obtained for a printout by summing over the appropriate subclasses in the distributed delay. The picture of a cabbage plant on the screen gives the user an approximate idea of what the predicted damage on the cabbage crop would look like.

\section{Validation}

Methods. Validation analysis was performed to demonstrate how well the model predicts data that were not used in model design or parameterization. Data collected by a commercial field monitoring and pest control advising service were used to compare model predictions with observed population densities and feeding damage $7 \mathrm{~d}$ after the original 


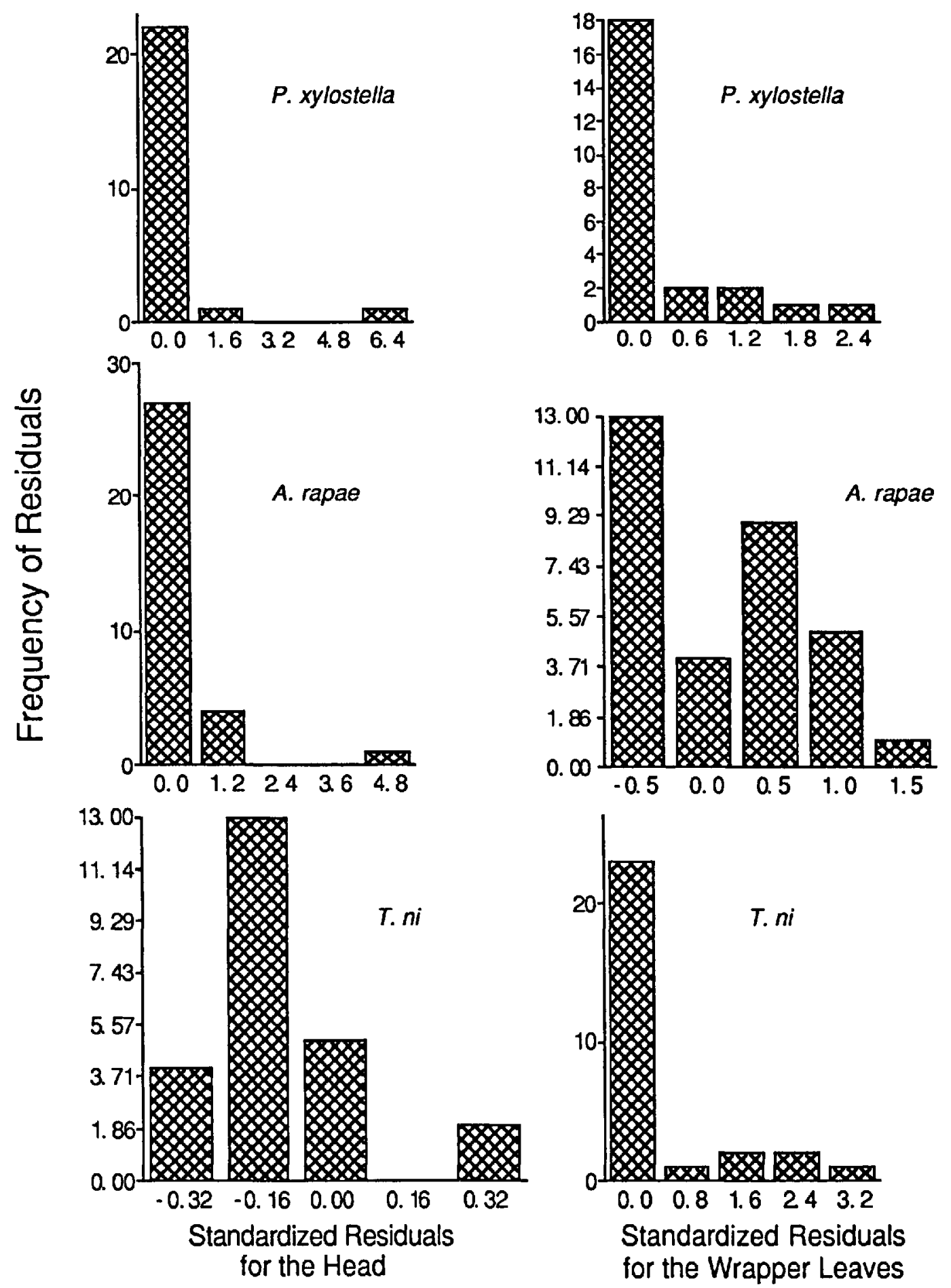

Fig. 5. Histograms of standardized cell residuals for comparing predicted numbers with observed average numbers of larvae on the cabbage head and wrapper leaves in commercial cabbage fields near Geneva, N.Y.

sample. Scouts sampled cabbage fields on a weekly basis, using a variable-intensity sampling scheme: (Hoy et al. 1983). Separate counts of $P$. xylostella. larvae (all instars combined), and $A$, rapae and $T$. $n i$ eggs, small (first and second instars) and large: (third, fourth, and fifth instars) larvae were taken on the head (stratum 1), wrapper (stratum 2), and frame leaves (strata 3-5 combined), and were used to initialize the model. Predictions of numbers of $P$. xylostella, large $A$. rapae, and $T$. ni, and accumulated feeding on the head and wrapper leaves were compared with the scout's observations taken 

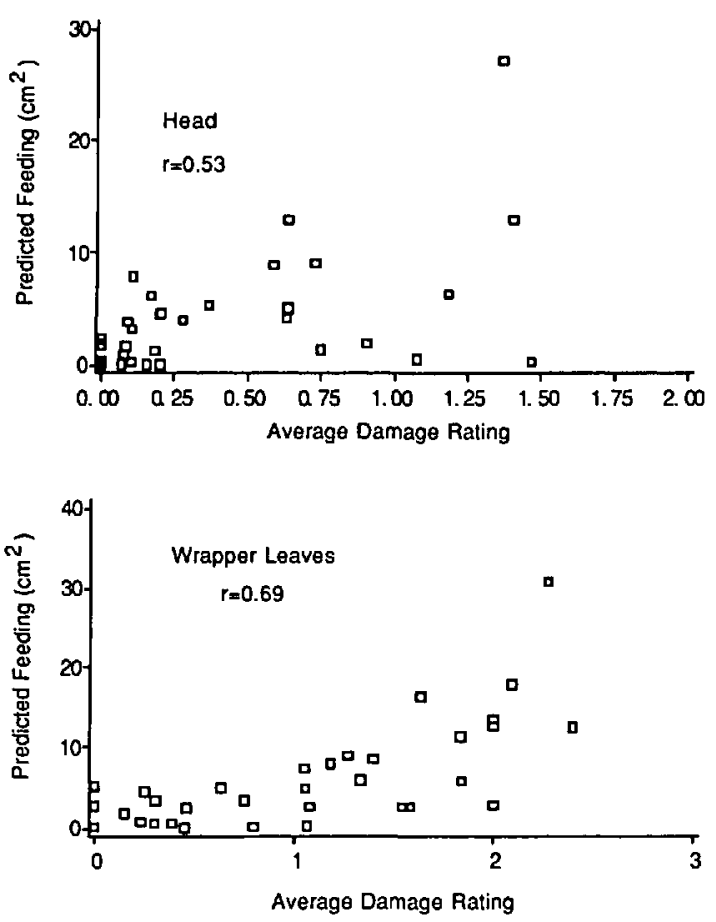

Fig. 6. Comparison of predicted feeding damage with average observed damage rating on the heads and wrapper leaves of commercial cabbage crops near $\mathrm{Ge}$ neva, N.Y.

the following week. Initial spatial distribution within the frame and initial age distribution with $A$. rapae and $T$. ni small and large larval populations were assumed to be uniform, for lack of more precise information. The scout's observations included ratings of feeding damage on a scale of 0 to 4 , indicating approximately no damage, less than one feeding hole per leaf, one to three feeding holes per leaf, $10 \%$ defoliation, and $\geq 40 \%$ defoliation, respectively. These ratings were compared with predictions of accumulated area of feeding with scatter plots and correlation analysis.

Weather data for model inputs (maximum and minimum temperatures and daily total solar radiation) were recorded at the New York State Agricultural Experiment Station in Geneva, N.Y., the closest weather station to the commercial fields being monitored (within $20 \mathrm{~km}$ ). Data from 34 pairs of field samples-each pair taken one week apart during July, August, and September in 1983 and 1984, under widely varying weather conditions-were used for this analysis.

Model predictions for number of larvae on the head and wrapper leaves were compared with observations using standardized cell residuals given by,

observed no. larvae - predicted no. larvae

$$
\sqrt{\text { predicted no. larvae }}
$$

as described by Bishop et al. (1975). These approximate a standard normal distribution, so the criterion for evaluation is whether or not most of the residuals are within $2 \mathrm{SD}$ of the mean $(\geq-2$ and $\leq 2$ ), because $\approx 95 \%$ of the standard normal distribution falls within this range. Observations of the feeding damage rating also were plotted against predicted accumulated area of feeding, and associated correlation coefficients were calculated.

Results and Discussion. Most standardized cell residuals for predicted versus observed counts of larvae on the head and wrapper leaves were well within the range -2 to +2 (Fig. 5). The few large deviations that were calculated were positive, indicating that, occasionally, greater average numbers of larvae than predicted were observed. The interplant spatial distribution of each species is aggregated (Harcourt 1966), and sample sizes were often small (as few as 11 plants) so these occasional large positive deviations are not surprising. These results indicate that the model predicts number and location of larvae well, particularly when the low resolution in the data for initial age and spatial distribution within the frame and potential sampling error in both samples are considered. Conclusions from this analysis must be tempered somewhat, however, by the low population densities observed in these fields. Bishop et al. (1975) warn that the approximation of the standardized cell residuals to the standard normal is poorest when predictions in the cells are small. Most of the initial population densities and associated predictions were small, because pest population densities are kept low by farmers. Evaluation of the model under these conditions is most appropriate, however, because these are the conditions under which the model would be used.

Predicted area of feeding was correlated with observed damage rating (Fig. 6). Damage rating included assessment of recent feeding, as well as older damage done before the first sample. This could explain circumstances in which little feeding damage was predicted, but high damage ratings were observed. Cases where large amounts of feeding damage were predicted but observed damage rating was low did not occur. Feeding damage is the most important variable to managers, because it determines the market value of the crop. The data indicate that the model can be used to predict the effects on the cabbage crop of a given pest population under specific conditions.

\section{Evaluation of Existing Treatment Guidelines}

Because the model predicts numbers of larvae and feeding damage on different parts of the plant well, model predictions can be used to evaluate treatment guidelines currently in use for cabbage pest management. In particular, the model can be used to explore the relative effects of each pest on the crop and how useful a static threshold for pest population density will be in predicting a given 

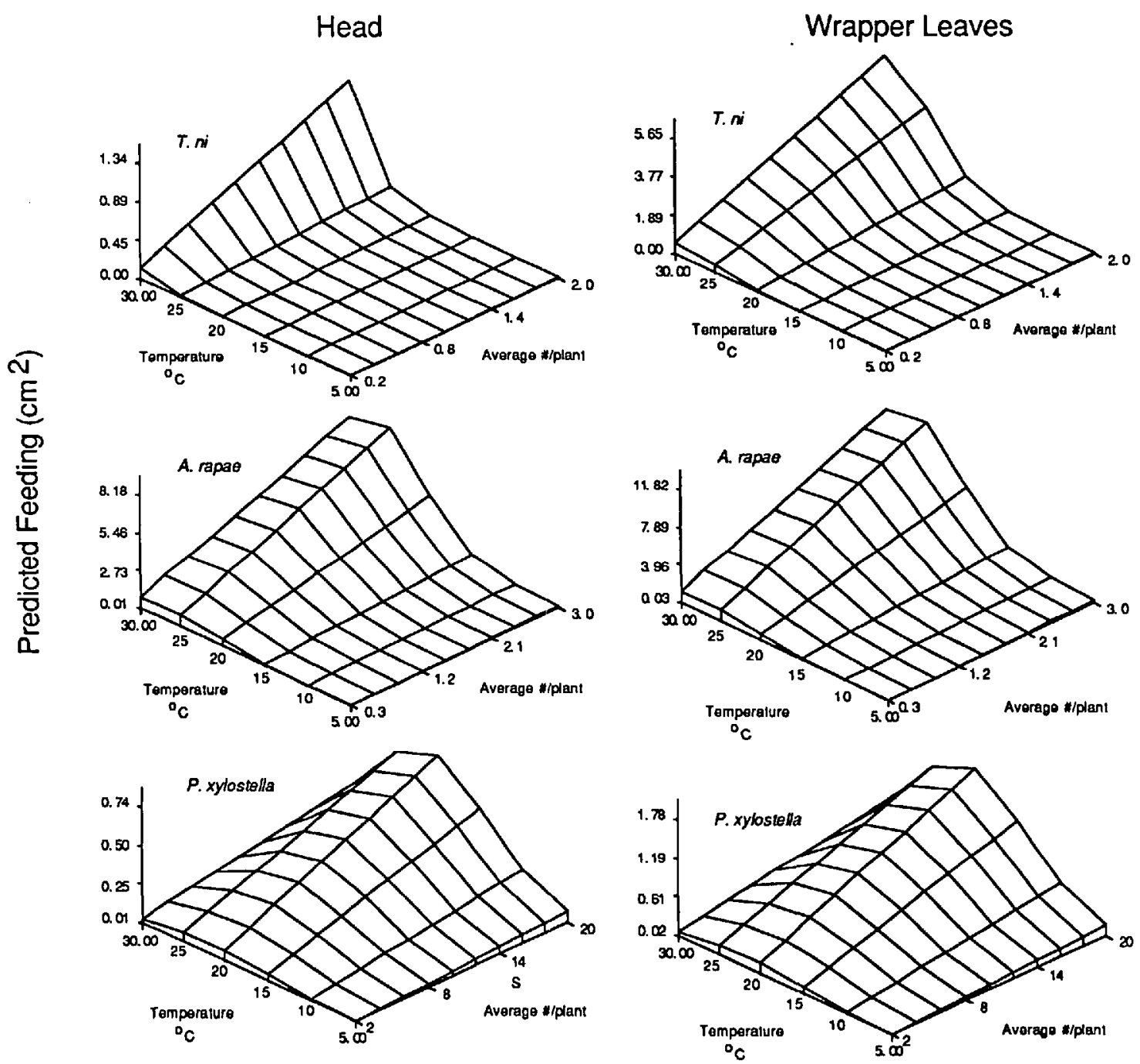

Fig. 7. Predicted average accumulated area of feeding on the cabbage head and wrapper leaves after $7 \mathrm{~d}$ at different temperatures and population densities of lepidopteran pests.

amount of damage on the marketable parts of the crop.

Methods. Response surfaces of predicted area of feeding on the head and wrapper leaves to temperature and population density of each pest were generated with the model. A standard initial intraplant spatial distribution, typical of distributions observed in cabbage fields, was chosen for each species as follows: $P$. xylostella, $0.05,0.1,0.3,0.3$ and $0.25 ; A$. rapae, $0,0.15,0.4,0.3$, and $0.15 ; T$. $n i, 0,0.1,0.2,0.4$, and 0.3 of the average number per plant on the head, wrapper leaves, upper frame, midframe, and lower frame, respectively. For $P$. $x y$ lostella, the larval ages were uniformly distributed among the 20 subclasses in the distributed delay. For $A$, rapae and $T$. ni, the larvae were initialized into the first 10 subclasses, simulating first, second, and third instars. For each of 10 population densities, ranging from well below to well above the action threshold currently used in New York (Shelton et al. 1982), feeding was predicted at six constant temperatures.

Additional response surfaces were generated of feeding area on the head and wrapper leaves predicted at different temperatures and initial age distributions for a given population density of each species. Given the initial spatial distribution described above and an average temperature between 20 and $25^{\circ} \mathrm{C}$, the first set of response surfaces was used to select a population density predicted to cause damage most farmers would consider unacceptable. This density, twice the currently recommended action threshold, was 1 larva/plant for T. $n i, 1.5$ larvae/plant for A. rapae, and 10 larvae/ plant for $P$. xylostella. Different age distributions were generated by dividing the population densities chosen above evenly among larval maturity subclasses 1 through 6 , then 2 through 7 , etc., up 

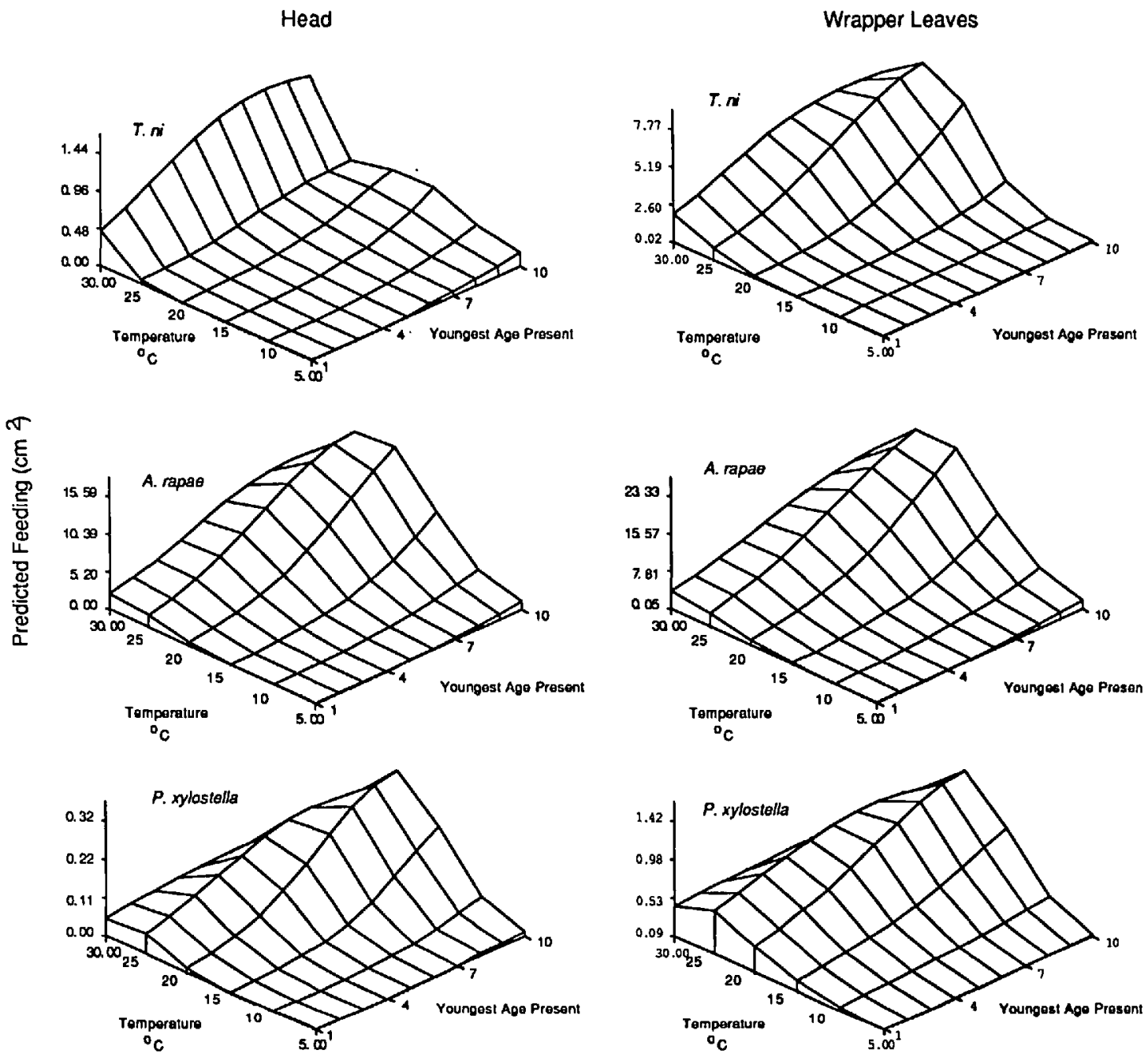

Fig. 8. Predicted average accumulated area of feeding on the cabbage head and wrapper leaves in $7 \mathrm{~d}$ due to different temperatures and age distributions at a given population density of three lepidopteran pests of cabbage. Population densities were $1 /$ plant for $T$. ni, 1.5/plant for A. rapae, 10/plant for P. xylostella.

to 10 through 15 . Model predictions were generated at each of these age distributions, for each of the 6 constant temperatures used above.

Results and Discussion. Response surfaces generated with the model predict that $A$. rapae contributes most to feeding damage on the head and wrapper leaves (Fig. 7). Although total consumption by $A$. rapae larvae is less than that of $T, n i$ (Harcourt et al. 1955), the amount consumed on these economically important strata is greater, because of the difference in intraplant spatial dynamics of the two species. In Fig. 7, the model predicts that for a given constant temperature and given initial age and spatial distributions, feeding on the head and wrapper leaves increases linearly with population density for each species. Systems that weight the counts of each species according to expected feeding damage and base the action threshold on the weighted counts have been proposed
(Harcourt et al. 1955, Shelton et al. 1982), but these did not consider the spatial dynamics of the pests. Thus, one potential use of our model is to design a new rating scale to weight the population density of each species according to expected feeding damage, considering the spatial dynamics of each species. This rating scale, however, would also have to account for temperature effects, which can greatly affect predicted feeding.

At temperatures $<15^{\circ} \mathrm{C}$, very little feeding is predicted on the head and wrapper leaves by each species at any population density (Fig. 7). Increasing temperatures have a nonlinear effect on predicted feeding by each species. For $P$. xylostella and $A$. rapae, the increase in predicted feeding rate may be primarily due to increased development and feeding rates. For T. $n i$, however, increased development and feeding rates at higher temperatures may be offset to some extent by higher 
probabilities of moving away from the head and wrapper leaves towards the lower leaves (Hoy et al. 1989).

For a given population density, predicted feeding on the marketable parts of the plant varied widely with age distribution, again interacting with temperature (Fig. 8). The results indicate that the damage caused by a given population density, a fixed economic threshold for example, will vary considerably with temperature, age structure of the population, and species composition. Again, weighting systems have been described that consider larval age (Andaloro et al. 1983a), but not with the resolution that Fig. 8 implies is necessary, and they do not include the interaction with temperature.

Considering the profound effects of temperature, age distribution, and species-specific spatial dynamics on the predicted area of feeding on economically important parts of the plant, a static economic threshold does not seem to be appropriate. Rather, feeding should be predicted for specific population densities, age distributions, and spatial distributions of the three species, as well as weather forecasts; and management strategies should be designed accordingly. The model described here could be used to make those predictions, either by cal. culating a new species weighting system each day of the growing season to be used with a fixed action threshold, or simply by making the required predictions on a case-by-case basis.

\section{Sensitivity Analysis}

Two goals were addressed in the sensitivity analysis. First, individual model parameters were eval-. uated as potential causes of inaccurate predictions. By examining the change in model output after a change in the individual parameters, parameters that affect the output most can be identified. Second, by examining the effects of changes in different parameters in combination, insight can be gained into the effects of the different processes being simulated, and their interactions, on the output variables of interest.

Methods. Model predictions were evaluated after changing each parameter and input supplied by the user by $+10 \%$ and $-10 \%$ of its value. Changes were made one parameter at a time, with a standard set of initial conditions. Standard initial pest population densities were a mean of 1 larva/ plant of each species on each stratum, in the second instar for $A$. rapae and $T$. $n i$, and uniformly distributed among the 20 age subclasses for $P$. xylostella. The analysis was performed at each of three temperature regimes: typical summer weather for western New York (maximum temperature, $26.7^{\circ} \mathrm{C}$; minimum temperature, $15.5^{\circ} \mathrm{C} ; 8 \mathrm{~h}$ sunshine each day), hot and sunny weather (maximum temperature, $32.2^{\circ} \mathrm{C}$; minimum temperature, $21.1^{\circ} \mathrm{C} ; 12$ $h$ sunshine each day), and cool and cloudy weather (maximum temperature, $18.3^{\circ} \mathrm{C}$; minimum temperature, $10^{\circ} \mathrm{C} ; 2$ h sunshine).

Constants were changed by adding or subtracting $10 \%$ of their value. Input weather variables were changed by adding or subtracting $10 \%$ of the value of each day's forecasted maximum and minimum temperature and hours of sunshine. Age at which larvae begin to move was shifted plus or minus two subclasses to effect a $10 \%$ change. Initial age distribution for $A$. rapae and $T$. ni was also shifted $10 \%$ by shifting the subclasses initialized by plus or minus two. Initial age distribution for $P$. xylostella is assumed to be uniform, so this was not changed. For each species, the initial intraplant distribution was altered by shifting $10 \%$ of each age group on each stratum, except the lower frame leaves, down one stratum, or shifting $10 \%$ of each age group on each stratum, except the head, up one stratum (e.g., a downward shift of an average of one larva on each stratum would result in an average of $0.9,1,1,1$, and 1.1 larvae on the head, wrapper, upper frame, midframe, and lower frame leaves, respectively). Transition probabilities for $A$. rapae and $P$. xylostella were changed by a similar method, shifting $10 \%$ of the probability of moving to each stratum except the lower frame leaves to the next lower stratum, or shifting $10 \%$ of the probability of moving to each stratum except the head to the next stratum up (e.g., a downward shift in a transition probability vector of 0.90 .1000 results in a vector of 0.810 .180 .0100 ). Sensitivity to changes in transition probabilities for $T$. $n i$ were examined by changing the Beta pdf shape parameters that govern transition probabilities for this species by $+10 \%$ and $-10 \%$ of their value. The effects of each of these changes were examined by calculating the percentage of change in number of larvae of each species, and the percentage of change in accumulated area of feeding, on the head and wrapper leaves.

To examine interactions between different processes and their effects on model output, we performed two analyses in which variables suspected of interacting were varied in all combinations, the equivalent of a factorial design with three levels of each factor, given by $+5 \%,-5 \%$, and $0 \%$. Because development and feeding rates are temperature-dependent and govern the amount of feeding accumulated, interactions between temperature, feeding rates, and development rates might affect accumulated area of feeding. Three levels of temperature were generated, starting with the typical summer weather regime described above and adding $5 \%,-5 \%$, or $0 \%$ of the daily maximum and minimum. At each temperature level, development rate for each species was varied by $+5 \%$, $-5 \%$, and $0 \%$ from its value, and at each of these development rates for each species, feeding rate was changed by $+5 \%,-5 \%$, and $0 \%$ of its value. The effects of these parameter changes on the predicted area of feeding on the head and wrapper leaves were calculated. 
Table 2. Output from a model to predict lepidopteran feeding damage on cabbage at three lemperature regimes with a standard set of inputs and no change in the parameters. Changes in output during the sensitivity analysis (Fig. 9-12) are compared with these standards

\begin{tabular}{|c|c|c|c|c|}
\hline \multirow{2}{*}{ Stratum } & \multicolumn{3}{|c|}{ Population density (avg no./plant) } & \multirow{2}{*}{$\begin{array}{c}\text { Feeding, } \\
\mathrm{cm}^{2}\end{array}$} \\
\hline & P. xylostella & A. rapae & $T . n i$ & \\
\hline \multicolumn{5}{|c|}{ High temperatures } \\
\hline $\begin{array}{l}\text { Head } \\
\text { Wrapper }\end{array}$ & $\begin{array}{l}0.252 \\
0.390\end{array}$ & $\begin{array}{l}2.118 \\
2.594\end{array}$ & $\begin{array}{l}0.095 \\
0.662\end{array}$ & $\begin{array}{l}12.764 \\
21.716\end{array}$ \\
\hline \multicolumn{5}{|c|}{ Moderate temperatures } \\
\hline $\begin{array}{l}\text { Head } \\
\text { Wrapper }\end{array}$ & $\begin{array}{l}0.423 \\
0.578\end{array}$ & $\begin{array}{l}1.957 \\
2.524\end{array}$ & $\begin{array}{l}0.299 \\
1.001\end{array}$ & $\begin{array}{l}6.805 \\
9.667\end{array}$ \\
\hline \multicolumn{5}{|c|}{ Low temperatures } \\
\hline $\begin{array}{l}\text { Head } \\
\text { Wrapper }\end{array}$ & $\begin{array}{l}0.635 \\
0.834\end{array}$ & $\begin{array}{l}1.296 \\
1.651\end{array}$ & $\begin{array}{l}0.829 \\
0.886\end{array}$ & $\begin{array}{l}1.945 \\
2.348\end{array}$ \\
\hline
\end{tabular}

A similar analysis of interacting processes was performed for spatial effects. Initial distribution and transition probabilities could be expected to interact in their effects on spatial distribution of larvae and feeding damage. For each species the initial distribution was treated by (a) shifting $10 \%$ of each age group on each stratum (except the lower frame leaves) down one stratum, (b) shifting $10 \%$ of each age group on each stratum (except the head) up one stratum, and (c) leaving the initial distribution unchanged. At each of these shifts in initial distribution for each species, the transition probabilities for that species were changed as de- scribed above. Shifting $10 \%$ of the probability of moving to each stratum except the lower frame leaves to the next lower stratum resulted in higher probabilities of downward movement; shifting $10 \%$ of the probability of moving to each stratum except the head to the next stratum up resulted in higher probability of upward movement.

Results and Discussion. Standard results for high, moderate, and low temperature regimes, without changing any of the parameters or input variables, are given in Table 2 , and the effects of changing each parameter and input variable on selected output variables are displayed in Fig, 9-12 for the moderate temperature regime. We begin the analysis by examining sensitivity of the model to changes in the parameters at moderate temperatures and follow with the differences in model sensitivity seen under high and low temperature regimes.

At moderate temperatures, numbers of larvae of each species on the head and wrapper leaves were least sensitive to initial spatial distribution of larvae, dispersion in development time, and hours of sunshine (Fig. 9). Change in the initial intraplant distribution of larvae may be compensated for by movement of larvae within a short time after the beginning of the simulation. Dispersion in development time for these species was low in the laboratory development studies, resulting in a small value of $\frac{S_{s}^{2}}{D E L_{s}^{2}}$ for each species. A $10 \%$ change in these small values does not change the dispersion

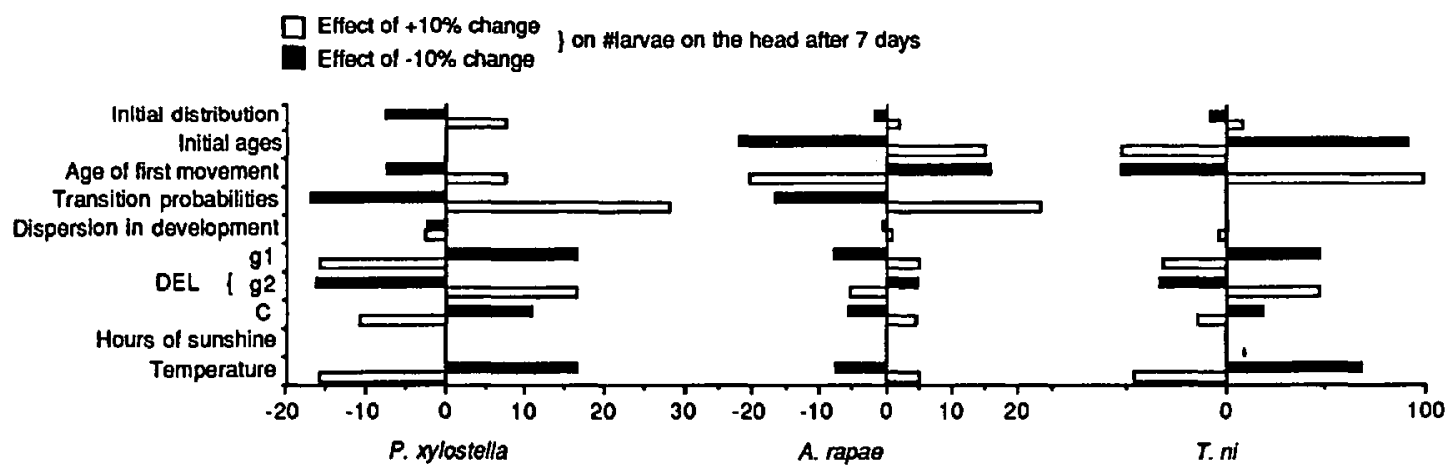

On Hlarvae on the wrapper leaves after 7 days

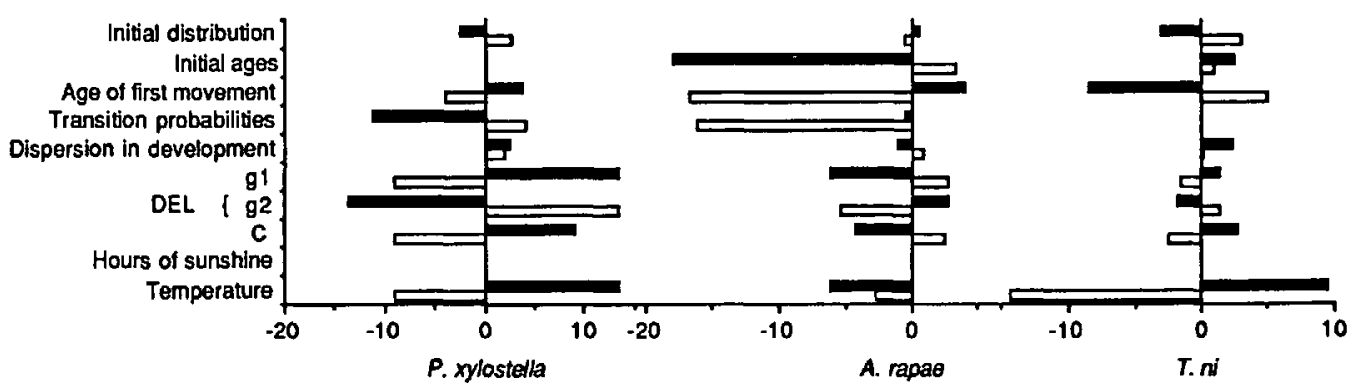

Fig. 9. Percentage of change in predicted number of $P$. xylostella, A. rapae, and T. ni larvae on the head and wrapper leaves after changing model parameters + and $-10 \%$. 

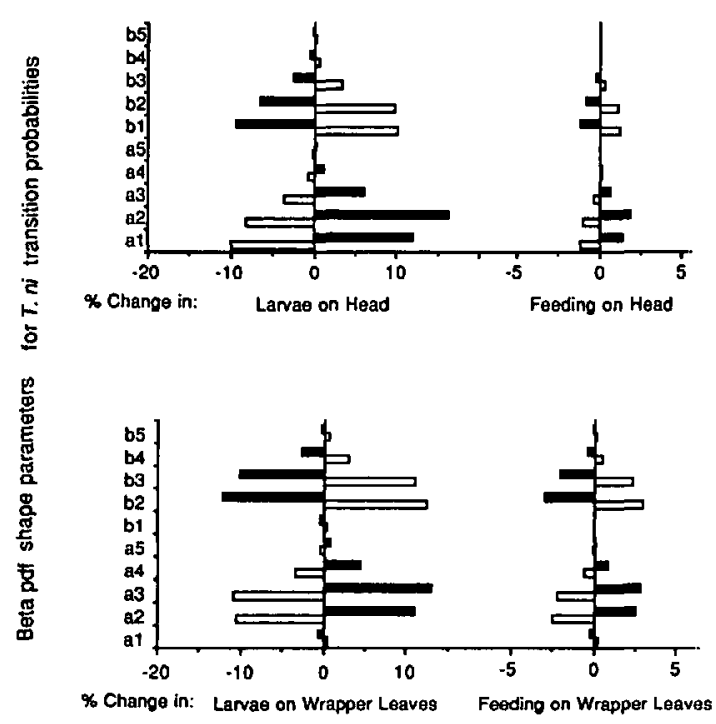

Fig. 10. Percentage of change in number of $T$. ni larvae predicted on the head and wrapper leaves after $a+$ or $-10 \%$ change in parameters governing their transition probabilities on the cabbage plant.

greatly. Hours of sunshine influence temperature in each stratum, but apparently not enough to cause large changes in rate functions.

Changes in temperature, initial age distribution, age at which larvae begin to move between strata, and transition probabilities had the greatest effects on predicted number of larvae on the head or wrapper leaves (Fig. 9). These are all linked to spatial dynamics, since both temperature and initial age distribution affect the time at which larvae begin to move between strata. Changes in parameters governing $T . n i$ transition probabilities were an exception, causing only moderate or small changes in output (Fig. 10). Changes in development rate parameters had large effects only for $P$. xylostella on the head and wrapper leaves and for T. $n i$ on the head.

Predictions of accumulated feeding on the head and wrapper leaves were generally less sensitive to changes in parameters than were predictions of numbers of larvae on these strata (Fig. 11 and 12). Because the predictions of accumulated area of feeding are most important to the farmer, the robustness of the model in predicting feeding suggests that it could be a useful management tool. The greatest changes in accumulated area of feeding were caused by changing parameters governing A. rapae development or feeding, particularly initial age distribution. Fortunately, development rates for all three species considered here have been well studied, and studies done at widely different times and locations with different food sources suggest that average development rate at a given temperature is fairly constant (Hardy 1938; Richards 1940; Given 1944; Miner 1947; Harcourt et al. 1955; Shorey et al. 1962; Jackson et al. 1969; Toba et al.
1973; Boldt et al. 1975; Butler et al. 1975; Smith \& Smilowitz 1976; Chen \& Su 1978, 1982; Tatchell 1981; Yamada \& Kawasaki 1983; Theunissen et al. 1985). Changes in forecast temperatures cause the next largest change in accumulated feeding, probably because of their effects on development and feeding rates. Parameters governing spatial effects had smaller effects on accumulated feeding, particularly when compared with their effects on predicted number of larvae on different parts of the plant.

Under the low-temperature regime, predictions of numbers of larvae on the head and wrapper leaves were more sensitive to parameters affecting development than to parameters affecting spatial dynamics. At low temperatures, larvae take longer to reach the age when movement starts, and probability of movement by $T$. $n i$ to the head and wrapper leaves is lower. Furthermore, fewer small larvae become large larvae at low temperatures, so total numbers of large larvae on all strata are reduced. At moderate and high temperatures, predictions of numbers of larvae on the head and wrapper leaves were more sensitive to changes in parameters affecting spatial dynamics.

Effects of changing forecast temperatures on predictions of accumulated feeding were much greater when the forecast temperatures were low, and less when the forecast temperatures were high, than at moderate temperatures. Changing development rate parameters had a greater effect on accumulated feeding at low temperatures, but changing feeding rate parameters had a greater effect at high temperatures than at moderate temperatures. Accumulated feeding was less sensitive to changes in transition probabilities at low temperatures, and more sensitive to changes in transition probabilities at high temperatures, than at moderate temperatures.

In general, interactions between temperature, development, and feeding rates, as well as parameters governing spatial effects, were not evident. Typically, the effect of changes in each of these parameters was similar regardless of the value of the other parameters. One interaction did occur: When temperature was increased, a negative change in $T . n i$ development rate resulted in less predicted feeding on the head than when no change in $T . n i$ development rate was made. In all other cases negative change in development rates resulted in higher predicted feeding on the head than when development rates were not changed. Regardless, 5\% changes in development rates for $T$. $n i$ resulted in $<3 \%$ differences in feeding on the head, so the effects of this interaction are not of great importance. Thus, this analysis reinforced the single parameter analysis. Feeding rates themselves were changed in this analysis, rather than the parameters that govern them, and accumulated feeding on the head and wrapper leaves was still more sensitive to changes in development rate and temperature. 

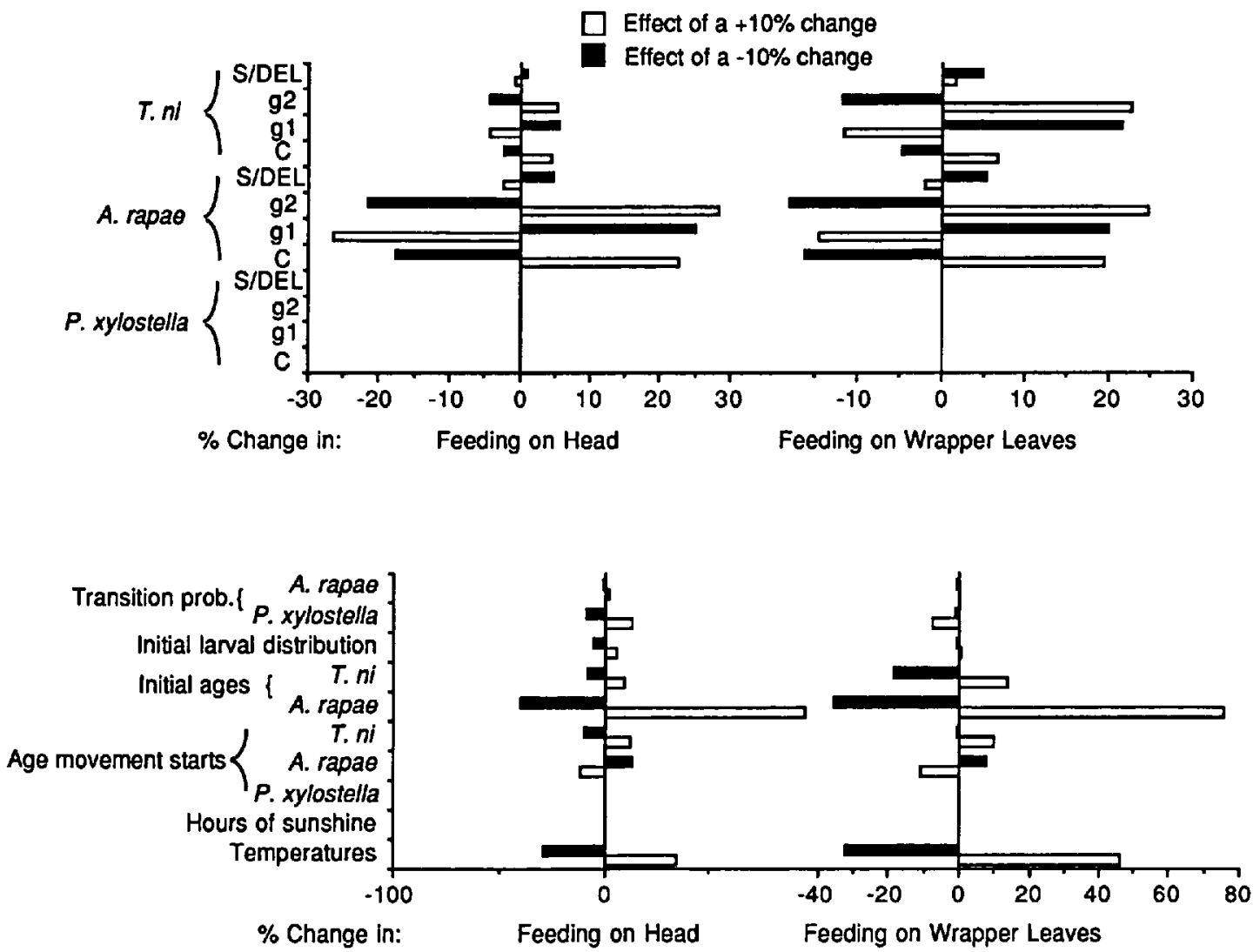

Fig. 11. Percentage of change in predicted accumulated area of feeding on the head and wrapper leaves, as a result of changing model parameters by + and $-10 \%$.

The sensitivity analyses suggest some important implications for use of the model. First, because the model was quite sensitive to initial age distribution and temperatures, a user should exercise great care in collecting data for inputs. Sampling for pests should be intensive enough to estimate the age distribution of each species accurately. Fur- thermore, because the insects within an instar are assumed to be uniformly distributed in age within the instar, erroneous predictions could be made if larval ages are more synchronous (e.g., all small larvae are within a few hours of eclosion). Insects in the field are usually not highly synchronous in their development because of different times of

Feeding Rates

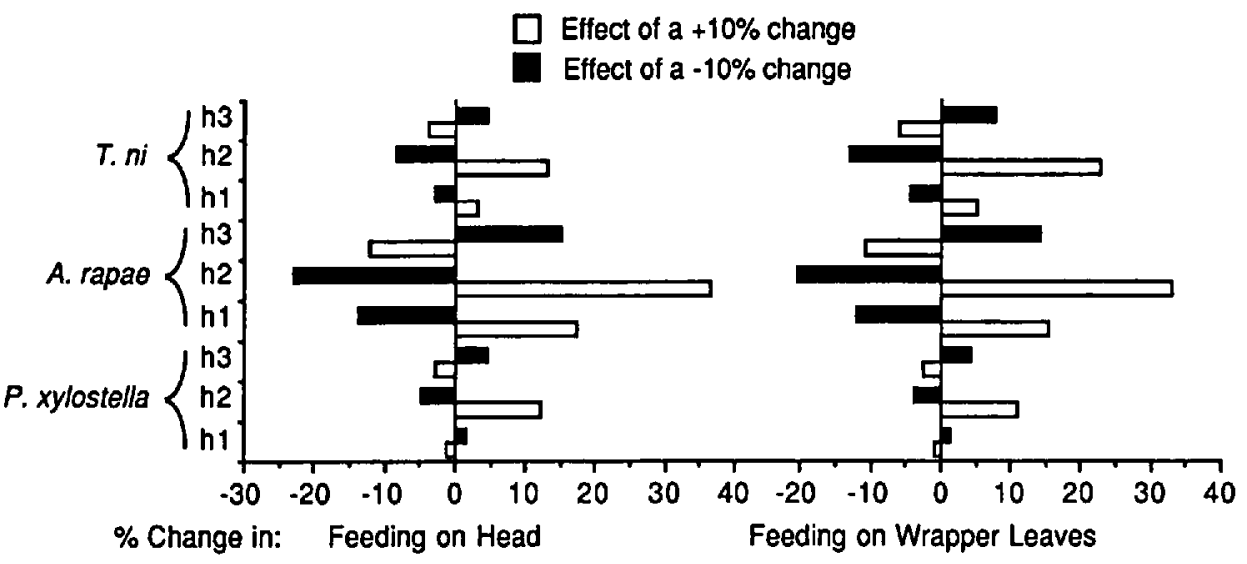

Fig. 12. Percentage of change in predicted accumulated area of feeding by Lepidoptera on cabbage heads and wrapper leaves after $a+$ or $-10 \%$ change in feeding rate parameters. 
oviposition and individual variation in development rate. Insecticides, however, can create more synchrony in larval ages by killing some life stages and not others. Errors are also likely to occur because of erroneous weather forecasts, and extended forecasts from the National Weather Service could be inaccurate enough to result in such errors. Weather forecasts used should be as recent as possible and as specific as possible to the local area being simulated in the model.

A second consideration is that predictions of number of larvae of a given species on a given stratum may be less precise than predictions of accumulated feeding, because the predictions of number of larvae on a given stratum are more sensitive to changes, or imprecision, in model parameters. Managers should be more concerned with predicted feeding anyway, because this is the variable that determines value of the crop. In making decisions, predictions of feeding should be stressed as the most robust indicator of economic damage, and the output variable for which the model is most robust. The predictions of number of larvae can be used to support decisions based on predictions of feeding damage, and perhaps to help target the most damaging species when selecting an insecticide or other treatment.

Finally, these analyses suggest two areas in which additional work to improve the model would be most useful: transition probabilities for $P$. xylostella and $A$. rapae, and the microclimate submodel. Changing transition probabilities for $P$. xylostella and $A$. rapae had large effects on predicted number of larvae on the head and wrapper leaves. The values used for these matrices reflect our observations and descriptions in the literature of movement by larvae of these species. Qualitatively the matrices fit these observations well, but each transition probability was not estimated quantitatively. Temperature affects not only the direction of movement by $T$. $n i$, but also the overall probability of movement (Hoy et al. 1989). Temperature could affect movement of the other two species as well, with the same proportion of larvae that do move going to a given stratum, but different proportions of larvae moving at different temperatures. Techniques developed to model movement as a function of environmental conditions for T. ni may be useful for the other two species.

Temperature itself within the canopy has been represented with a simple, descriptive model. This description is based on an understanding of the energy budget within a crop canopy, but that energy balance can itself be modeled more mechanistically. Unfortunately, a more mechanistic treatment would require consideration of more weather conditions. Specifically, heat loss due to convection would require estimates of wind speed, and evaporative heat loss would require estimates of ambient humidity. Because these cannot be predicted nearly as reliably as temperature, they were not included in this first version of the model. However, given the sensitivity of the model to temperature, making use of whatever predictions are available in a more sophisticated and mechanistic microclimate model may improve reliability of predictions of numbers of larvae on given plant strata and predicted area of feeding on those strata.

\section{Conclusions}

The simulation model described here has allowed us to estimate the importance of intraplant spatial dynamics in determining when and how much damage will occur on the marketable parts of a crop. We have learned from the model that these dynamics have an important effect on the amount of damage incurred on the marketable parts of the plant resulting from a given combination of population densities of pest species and environmental conditions. We maintain that these effects are important enough to warrant the use of a more complex model than the static threshold population density in making management decisions for the system we have studied.

A manager using this model would supply a weather forecast and results of a field sample to generate predictions of feeding damage. If minimal or no damage is forecast on the head and wrapper leaves for the next $7 \mathrm{~d}$, no treatments would be applied to the crop. If unacceptable levels of feeding were forecast during the $7-\mathrm{d}$ period, the manager would look at the output for each day to determine when unacceptable levels were forecast to appear. Until the manager has gained some experience in using the model, a conservative limit for allowable damage would probably be used. A treatment, usually an insecticide application, would be applied to reduce the pest population before the damage is forecast to appear. Fine tuning of the timing of this application that would consider weather, schedule of other farm operations, and changing age structure of the pest population and resulting effectiveness of the insecticide is possible between the time the forecast is made and the time the unacceptable damage is forecast to appear. If the weather during this period is different from the forecast, the model could be rerun with the updated weather forecast for even more precise information.

We rely on the manager to decide what level of damage is unacceptable and to devise reasonable management strategies accordingly. Our experience has been that individual farmers have their own guidelines for acceptability developed through years of experience in marketing their product. Despite attempts to standardize quality guidelines, considerable variation seems to exist in what individual buyers are willing to accept, with accompanying variation in what they are willing to pay. No one understands these guidelines better than the buyer and seller, because the understanding is created between these two. The sellers, in this case, 
are also the pest managers who must plan ahead to meet the guidelines for the market chosen for their crop.

Use of the model in its present form is limited to an extent by the form of the output, the average area of feeding on a cabbage head and wrapper leaves. Percentage of marketable heads, which the manager is more interested in, depends on the mean and variance of feeding area on these plant parts; therefore, this version of the model does not predict the variable, percentage of marketable heads, that would allow direct calculation of expected cost of the pest infestation. The model incorporates only intraplant spatial dynamics of pests and their feeding damage; interplant dynamics would also have to be addressed to predict interplant distribution of damage. This prediction is possible, but will require additional research or computing. One way to predict percentage of marketable heads would be to run the simulation separately for each of the sampled cabbage plants, using the individual plant counts as inputs. The percentage of plants having less than a given amount of damage could then be estimated. This would require considerable additional computing. Another possibility would be to estimate empirically a relationship between the mean and variance of feeding area, if such exists. The variance and percentiles for given levels of damage could then be estimated as a function of the mean.

Finally, our sensitivity analysis has suggested parts of the model that further research could improve. Given the insensitivity of model output to some of the parameters, it may be possible to simplify some aspects of the model for management use. Sensitivity analysis also provided an indication of the precision required in sampling fields to obtain pest population density estimates for model inputs. This level of precision may require more sampling effort than is currently expended. Although our validation analysis examined the predictive capabilities of the model, the costs and benefits of using it for decision making should still be estimated and compared to current practice. Construction and analysis of the model in its present form, however, have yielded important new insights into intraplant spatial dynamics of insect pests, and how those dynamics affect the relationship of pest population density to crop damage.

\section{Acknowledgment}

We thank Gary W. Fick for his assistance with this work, and Robert C. Seem for patient help with weather monitoring equipment. We are also grateful to David W. Onstad and Stephen E. Naranjo for thorough and helpful reviews of an earlier draft of the manuscript. This work is part of a thesis submitted by Casey W. Hoy to the Cornell University Graduate School in partial fulfillment of the requirements for the degree of Doctor of Philosophy.

\section{References Cited}

Andaloro, J. T., C. W. Hoy, K. B. Rose, J. P. Tette \& A. M. Shelton. 1983a. A review of cabbage pest management in New York: from the pilot project to the private sector, 1978-1982. New York Food and Life Science Bulletin 105, New York State Agricultural Experiment Station, Cornell University, Ithaca.

Andaloro, J. T., K. B. Rose, A. M. Shelton, C. W. Hoy \& R. F. Becker. 1983b. Cabbage growth stages. New York Food and Life Science Bulletin 101, New York State Agricultural Experiment Station, Cornell University, Ithaca.

Bishop, Y. M. M., S. E. Fienberg \& P. W. Holland. 1975. Discrete multivariate analysis. MIT Press, Cambridge, Mass.

Boldt, P. E., K. D. Biever \& C. M. Ignoffo. 1975. Lepidopteran pests of soybeans: consumption of soybean foliage and pods and development time. J. Econ. Entomol. 68: 480-482.

Butler, G. D., Jr., A. G. Hamilton \& A. C. Bartlett. 1975. Development of the dark strain of cabbage looper in relation to temperature. Environ. Entomol. 4: 619-620.

Butler, G. D., Jr., R. E. Stinner \& G. L. Greene. 1976 Application of a thermodynamic model for the development of larvae of the cabbage looper (Lepidoptera: Noctuidae) at fluctuating temperatures. Fla Entomol. 59: 165-169.

Cartwright, B., J. V. Edelson \& C. Chambers. 1987. Composite action thresholds for the control of lepidopterous pests on fresh-market cabbage in the lower Rio Grande valley of Texas. J. Econ. Entomol. 80: 175-181.

Chalfant, R. B., W. H. Denton, D. J. Schuster \& R. B. Workman. 1979. Management of cabbage cater pillars in Florida and Georgia by using visual damage thresholds. J. Econ. Entomol. 72: 411-413.

Chen, C. \& W. Su. 1978. Influence of temperature on the development and feeding amount of diamondback moth larvae on cauliflower. Plant Prot. Bull. 20: 224-231.

1982. Influence of temperature on development and leaf consumption of three caterpillars on cauliflower. Plant Prot. Bull. 24: 131-141.

Chua, T. H. \& B. H. Lim. 1979. Distribution pattern of the diamondback moth Plutella xylostella (Lepidoptera: Plutellidae) on choy-sum plants. Z. Angew. Entomol. 88: 170-175.

Given, B. B. 1944. The relative food consumption of diamond-back moth and white butterfly larvae. $\mathrm{N}$. Z. Sci. Tech, 26(A): 195-197.

Goudriaan, J. 1973. Dispersion in simulation models of population growth and salt movement in the soil Neth. J. Agric. Sci. 2l: 269-281.

Greene, G. L., W. G. Genung, R. B. Workman \& E. G. Kelsheimer. 1969. Cabbage looper control in Florida-a cooperative program. J. Econ. Entomol. 62 : $798-800$.

Harcourt, D. G, 1963. Biology of cabbage caterpillars in eastern Ontario. Proc. Entomol. Soc. Ont. 93: 6175 .

1966. Major factors in survival of the immature stages of Pieris rapae (L.). Can. Entomol. 98: 653-662.

Harcourt, D. G., R. H. Backs \& L. M. Cass. 1955. Abundance and relative importance of caterpillars attacking cabbage in eastern Ontario. Can. Entomol. 87: 400-406.

Hardy, J. E. 1938. Plutella maculipennis Curt., its 
natural and biological control in England. Bull. Entomol. Res. 29: 343-372.

Harper, J. D. 1973. Food consumption by cabbage loopers infected with nuclear polyhedrosis virus. J. Invertebr. Pathol. 21: 191-197.

Hoy, C. W. \& A. M. Shelton. 1987. Feeding response of Artogeia rapae (Lepidoptera: Pieridae) and Trichoplusia ni (Lepidoptera: Noctuidae) to cabbage leaf age. Environ. Entomol. 16: 680-682.

Hoy, C. W., C. Jennison, A. M. Shelton \& J. T. Andaloro. 1983. Variable intensity sampling: a new technique for decision making in cabbage pest management. J. Econ. Entomol. 76: 139-143.

Hoy, C. W., C. E. McCulloch, C. A. Shoemaker \& A. M. Shelton. 1989. Transition probabilities for Trichoplusia ni (Lepidoptera: Noctuidae) larvae on cabbage as a function of microclimate. Environ. Entomol. 18: 187-194.

Jackson, C. G., G. D. Butler, Jr., \& D. E. Bryan. 1969. Time required for development of Voria ruralis and its hast the cabbage looper, at different temperatures. J. Econ. Entomol. 62: 69-70.

Jones, R. E. \& P. M. Ives. 1979. The adaptiveness of searching and host selection behaviour in Pieris rapae (L.). Aust. J. Ecol. 4: 75-86.

Kirby, R. D. \& J. E. Slosser. 1984. A composite economic threshold for three lepidopterous pests of cabbage. J. Econ. Entomol. 77: 725-733.

Leibee, G. L., R. B. Chalfant, D. J. Schuster \& R. B. Workman. 1984. Evaluation of visual damage thresholds for management of cabbage caterpillars in Florida and Georgia. J. Econ. Entomol. 77: 10081011.

Manetsch, T. J. 1976. Time-varying distributed delays and their use in aggregative models of large systems. IEEE Trans. Syst. Man Cybern. SMC-6, No. 8: 547-553

McEwen, F. L. \& G. E. R. Hervey. 1960. Mass rearing the cabbage looper, Trichoplusia ni, with notes on its biology in the laboratory. Ann. Entomol. Soc. Am. 23: $229-234$.

Miner, F. D. 1947. Life history of the diamondback moth. J. Econ. Entomol. 40: 581-583.

Morisak, D. J., D. E. Simonet \& R. K. Lindquist. 1984. Use of action thresholds for management of lepidopterous larval pests of fresh-market cabbage. J. Econ. Entomol. 77: 476-482.

Onstad, D. W. 1987. Calculation of economic-injury levels and economic thresholds for pest management. J. Econ. Entomol. 80: 297-303.

Pedigo, L. P., S. H. Hutchins \& L. G. Higley. 1986. Economic injury levels in theory and practice. Annu. Rev. Entomol. 31: 341-368.

Poston, F. L., L. P. Pedigo \& S. M. Weleh. 1983. Economic-injury levels: reality and practicality. Bull. Entomol. Soc. Am. 29: 49-53.

Rahman, M. 1970. Effect of parasitism on food consumption of Pieris rapae larvae. J. Econ. Entomol. 63: $820-821$

Richards, O. W. 1940. The biology of the small white butterfly (Pieris rapae) with special reference to the factors controlling its abundance. J. Anim. Ecol. 9: 243-288.
Salinas, P. J. 1984. Studies on the behavior of the larvae of Plutella xylostella (Linnaeus) (Lepidoptera: Plutellidae), a world pest of cruciferous crops. Normal and 'spacing' behaviour. Turrialba 34: 77-84.

Samson, P. R. \& P. W. Geier. 1983. Induction of crop damage by the cabbage white butterfly Pieris rapae (Lepidoptera: Pieridae) on cabbage. Prot. Ecol. 5: 199-234.

SAS Institute. 1982. SAS user's guide: statistics. SAS Institute, Cary, N.C.

Sears, M. K., R. P. Jaques \& J. E. Laing. 1983. Utilization of action thresholds for microbial and chemical control of lepidopterous pests (Lepidoptera: Noctuidae, Pieridae) on cabbage. J. Econ. Entomol. 76 368-374.

Shelton, A. M., J. T. Andaloro \& J. Barnard. 1982. Effects of cabbage looper, imported cabbageworm, and diamondback moth on fresh market and processing cabbage. J. Econ. Entomol. 75: 742-745.

Shelton, A. M., M. K. Sears, J. A. Wyman \& T. C. Quick. 1983. Comparison of action thresholds for lepidopterous larvae on fresh-market cabbage. J. Econ Entomol. 76: 196-199.

Shorey, H. H., L. A. Andres \& R. L. Hale. 1962. Biology of Trichoplusia ni (Lepidoptera: Noctuidae). I. Life history and behavior. Ann. Entomol. Soc. Am. 55: 591-597.

Smith, C. L. \& Z. Smilowitz. 1976. Growth and development of Pieris rapae larvae parasitized by Apanteles glomeratus. Entomol. Exp. Appl. 19: 189195.

Stern, V. M. 1973. Economic thresholds. Annu. Rev. Entomol. 18: 259-280.

Stinner, R. E., A. P. Gutierrez \& G. D. Butler, Jr. 1974. An algorithm for temperature-dependent growth rate simulation. Can. Entomol. 106: 519-524.

Tatchell, G. M. 1981. The effects of a granulosis virus infection and temperature on food consumption of Pieris rapae (Lepidoptera: Pieridae). Entomophaga 26: 291-300.

Theunissen, J., H. den Ouden \& A. K. H. Wit. 1985. Feeding capacity of caterpillars on cabbage, a factor in crop loss assessment. Entomol. Exp. Appl. 39: 255260.

Toba, H. H., A. N. Kishaba, R. Pangaldan \& P. V. Vail. 1973. Temperature and development of the cabbage looper. Ann. Entomol. Soc. Am. 66: 956-974.

Wolfson, J. L. 1982. Developmental responses of Pieris rapae and Spodoptera eridania to environmentally induced variation in Brassica nigra. Environ. Entomol. 11: 207-213.

Workman, R. B., R. B. Chalfant \& D. J. Schuster. 1980. Management of cabbage worms with two thresholds and five insecticidal sprays. J. Econ. Entomol. 73: 757-760.

Yamada, H. \& K. Kawasaki. 1983. The effect of temperature and humidity on the development, fecundity, and multiplication of the diamondback moth Plutella xylostella. Jpn. J. Appl. Entomol. Zool. 27: $17-21$

Received for publication 19 June 1989; accepted 18 May 1990. 